\title{
Trade Openness and Volatility
}

\author{
Julian di Giovanni \\ and \\ Andrei A. Levchenko
}





\title{
IMF Working Paper
}

\author{
Research Department
}

Trade Openness and Volatility

\section{Prepared by Julian di Giovanni and Andrei A. Levchenko*}

\author{
Authorized for distribution by Atish Ghosh
}

June 2008

\begin{abstract}
This Working Paper should not be reported as representing the views of the IMF. The views expressed in this Working Paper are those of the author(s) and do not necessarily represent those of the IMF or IMF policy. Working Papers describe research in progress by the author(s) and are published to elicit comments and to further debate.

This paper examines the mechanisms through which output volatility is related to trade openness using an industry-level panel dataset of manufacturing production and trade. The main results are threefold. First, sectors more open to international trade are more volatile. Second, trade is accompanied by increased specialization. Third, sectors that are more open are less correlated with the rest of the economy. The point estimates indicate that each of the three effects has an appreciable impact on aggregate volatility. Added together they imply that the relationship between trade openness and overall volatility is positive and economically significant.
\end{abstract}

JEL Classification Numbers: F15, F40

Keywords: Trade, Output Volatility, Specialization, Comovement, Sector-Level Data Author's E-Mail Address: JdiGiovanni@imf.org; ALevchenko@imf.org

\footnotetext{
* We would like to thank Fernando Broner, Andre Faria, Jean Imbs, Ayhan Kose, Akito Matsumoto, Enrique Mendoza, Eswar Prasad, Petia Topalova, Jaume Ventura, two anonymous referees, workshop and conference participants at the IMF, Centro Studi Luca d'Agliano/CEPR Conference on Trade, Industrialization and Development, CREI/World Bank/CEPR Conference on the Growth and Welfare Consequences of Macroeconomic Volatility, NBER IFM and ITI meetings, IMF Research Conference on Trade, Society for Economic Dynamics Annual Meetings, North American Summer Meetings of the Econometric Society, and especially Romain Rancière, for helpful suggestions. Priyanka Malhotra provided expert research assistance.
} 
I. Introduction

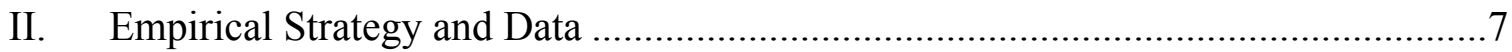

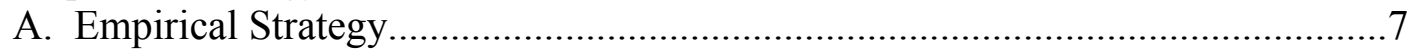

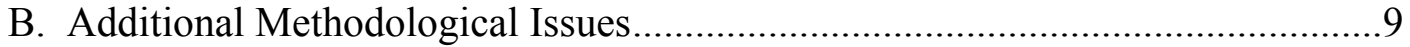

C. Data and Summary Statistics ..................................................................... 12

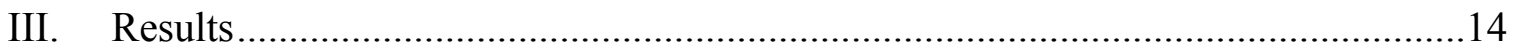

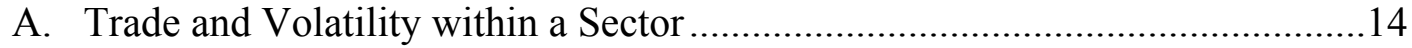

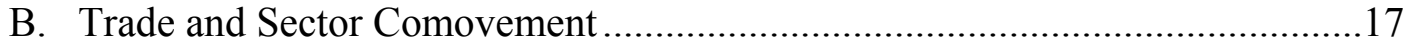

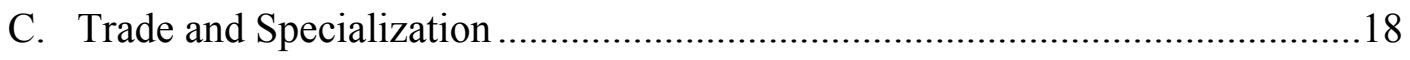

IV. The Impact on Aggregate Volatility ...........................................................19

A. The Relationship between Each Channel and the Aggregate Volatility ...........20

B. The Impact Across Countries and Over Time.................................................22

C. Country Characteristics and the Impact on Aggregate Volatility ....................24

D. Changes in the Impact on Aggregate Volatility Across Decades ....................26

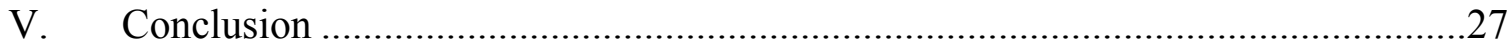

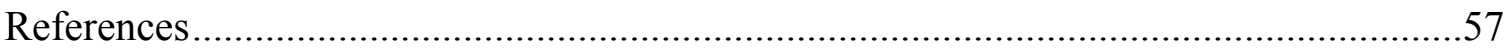

Text Tables:

1. Volatility of Annual Output Growth per Worker: Cross-Sectional Results ..............36

2. Volatility of Annual Output Growth per Worker: Panel Results................................36

3. Volatility of Annual Growth of Quantity per Worker and of Prices:

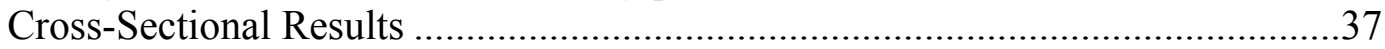

4. Volatility of Annual Growth of Quantity per Worker and of Prices:

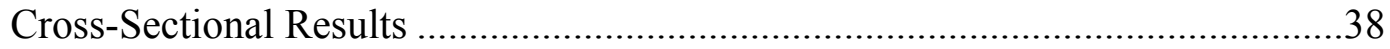

5. Correlation of Annual Output Growth per Worker with the Rest of the Manufacturing Section: Cross-Section Results ..................................................39

6. Correlation of Annual Output Growth per Worker with the Rest of the Manufacturing Section: Panel Results ................................................................40

7. Correlation of Annual Growth of Quantity per Worker and of Prices with Rest of the Manufacturing Section: Cross-Sectional Results ...............................41

8. Specialization and Trade Openness at the Country Level .....................................42

9. Volatility, Correlation and Specialization Coefficients Across Decades ..................43

10. Cross-Country and Cross-Decade Impacts of Changes in Openness .......................44

11. The Impact of Changes in Openness Evaluated at Different Percentiles of the Data 
Text Figures:

1. Volatility and Openness in the 1990's .46

2. Comparison of Manufacturing and Aggregate Volatility ........................................46

3. Manufacturing Output Volatility and Openness ...............................................47

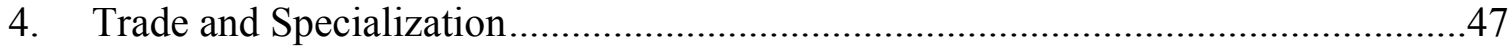

Appendices

I. Sector-Level Gravity-Based Instrument .........................................................28

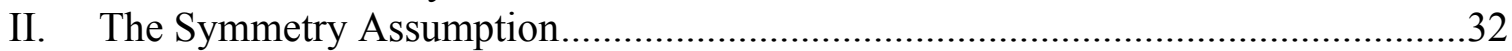

Appendix Tables:

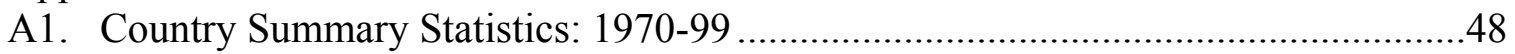

A2. Sector Summary Statistics: $1970-99$................................................................ 49

A3. Volatility of Annual Output Growth per Worker: Cross-Sectional Robustness

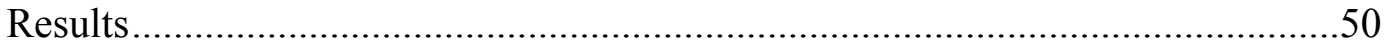

A4. Volatility of Annual Output Growth per Worker: Panel Robustness Results...........51

A5. Correlation of Annual Output Growth per Worker with Rest of the Manufacturing Sector: Cross-Sectional Robustness .........................................52

A6. Correlation of Annual Output Growth per Worker with Rest of the Manufacturing Sector: Panel Robustness Results..............................................53

A7. Specialization and Trade Openness at the Country Level: Robustness Results .......54

Appendix Figure A1. Sector-Level Gravity Coefficients ..........................................55 


\section{INTRODUCTION}

Macroeconomic volatility is considered an important determinant of a wide variety of economic outcomes. Numerous studies identify its effects on long-run growth (Ramey and Ramey 1995), welfare (Pallage and Robe 2003, Barlevy 2004), as well as inequality and poverty (Gavin and Hausmann 1998, Laursen and Mahajan 2005). The question of what are the main determinants of macroeconomic volatility has thus attracted a great deal of attention in the literature. In particular, it has been argued that trade openness plays a role (Rodrik 1997, ILO 2004). As world trade has experienced exponential growth in recent decades, understanding the relationship between trade and volatility has become increasingly important. Figure 1 shows a scatterplot of trade openness and the volatility of GDP growth in the 1990s for a large sample of countries, after controlling for per capita income. Differences in volatility are pronounced: countries in the $75^{\text {th }}$ percentile of the output volatility distribution exhibit a standard deviation of growth some three times higher than those in the $25^{\text {th }}$ percentile. At the same time, it appears that the correlation between openness and volatility is positive in the data. ${ }^{2}$

There is currently no consensus, either empirically or theoretically, on the nature of the relationship between trade openness and macroeconomic volatility. In part, this is because the mechanisms behind it are not well understood. For instance, does trade affect volatility primarily by exposing industries to external shocks? Or because it changes the comovement properties of the trading sectors with the rest of the economy? Or does trade affect volatility through its impact on the diversification of production across sectors $?^{3}$ The main purpose of this paper is to answer these questions by examining the relationship between trade openness and volatility using an industry-level panel dataset on production and trade. The use of industry-level data allows us to look into the individual channels through which trade can be related to aggregate volatility.

We begin by testing three hypotheses. The first is that trade openness is associated with changes in the volatility of individual sectors. For instance, it has been suggested that in an economy open to international trade, an industry is more vulnerable to world supply and demand shocks (Newbery and Stiglitz 1984). The second hypothesis is that greater trade openness comes with changes in comovement between sectors within the economy. For

\footnotetext{
${ }^{2}$ A number of cross-country empirical studies analyze the relationship between trade openness and volatility. Easterly, Islam and Stiglitz (2001) and Kose, Prasad and Terrones (2003) find that openness increases the volatility of GDP growth. Kose et al. (2003) and Bekaert, Harvey and Lundblad (2006) also find that greater trade openness increases the volatility of consumption growth, suggesting that the increase in output volatility due to trade is not fully insured away. Moreover, Rodrik (1998) provides evidence that higher income and consumption volatility is strongly associated with exposure to external risk, proxied by the interaction of overall trade openness and terms of trade volatility. Recent work by Bejan (2004) and Cavallo (2005) finds that openness decreases output volatility.

${ }^{3}$ Koren and Tenreyro (2007) emphasize that aggregate volatility can arise from volatility of individual sectors, patterns of specialization, and the covariance properties of sectors with the aggregate shocks.
} 
example, when a sector is very open, it may depend more on global shocks to the industry, and less on the domestic cycle (Kraay and Ventura 2006). This channel has not, to our knowledge, been investigated empirically in the literature. The third hypothesis is that trade is accompanied by changes in the pattern of specialization. For instance, if trade leads to a less diversified production structure, aggregate volatility will increase, and vice versa.

The main results can be summarized as follows. First, sectors more open to international trade are more volatile. Second, more trade in a sector is accompanied by a lower correlation between growth in that sector and aggregate growth, an effect that leads to a reduction in aggregate volatility, all else equal. Third, countries that are more open exhibit greater specialization, which works as a channel for creating increased volatility. The results are remarkably robust for all three channels, over different sized panels, and to the inclusion of a plethora of fixed effects, additional controls, and the use of instrumental variables.

Having estimated the three effects individually, we would like to establish whether these have an appreciable impact on aggregate volatility. It could be, for instance, that a rise in sector-specific volatility related to trade has a completely negligible impact on aggregate volatility, because on average countries are well diversified across sectors. Thus, we use the point estimates to calculate how important the three effects are quantitatively when it comes to their impact on aggregate volatility. It turns out that an increase in sector-level volatility associated with moving from the $25^{\text {th }}$ to the $75^{\text {th }}$ percentile in the distribution of trade openness - equivalent to a movement in the trade-to-output ratio of about 60 percentage points - raises aggregate volatility by about $10.2 \%$ of the average aggregate variance observed in the data, all else held equal. The reduction in comovement that comes with increased trade leads to a fall in aggregate volatility roughly equivalent to $6.3 \%$ of its average. Increased specialization in turn implies an increase in aggregate variance of $13.5 \%$. Adding up the three effects, these estimates imply that moving from the $25^{\text {th }}$ to the $75^{\text {th }}$ percentile in trade openness is associated with an increase in aggregate volatility of about $17.3 \%$ of the average aggregate variance observed in the data.

The impact of openness on volatility varies a great deal depending on country characteristics, however. For instance, we estimate that an identical change in trade openness is accompanied by an increase in aggregate volatility that is five times higher in the average developing country compared to the average developed country. Lastly, we estimate how the impact of trade changes across decades. It turns out that all three channels, as well as the overall effect, increase in importance over time: the impact of the same trade opening on aggregate volatility in the 1990s is double what it was in the 1970s. While our approach is silent on how or whether the nature of the underlying shocks has changed over this period, it is clear that trade has become an increasingly important conduit for their transmission through the world economy. ${ }^{4}$

\footnotetext{
${ }^{4}$ Note that this finding is not at all inconsistent with the common observation that aggregate volatility itself has diminished over the same time period, which is also true in our data.
} 
To summarize, all three channels - sector-level volatility, comovement, and specialization have a sizeable impact on aggregate volatility. It appears, however, that the comovement effect, which acts to reduce volatility, is considerably less important in magnitude than the other two. Thus, trade is associated with increased aggregate volatility, through its positive relationship to both sector-level volatility and specialization.

This paper uses data on production, quantity indices, employment, and prices for the manufacturing sector from the United Nations Industrial Development Organization (2006), and combines them with the World Trade Database (Feenstra et al. 2005) for the period 1970-99. The resulting dataset is a three-dimensional unbalanced panel of 61 countries, 28 manufacturing sectors, and 30 years. ${ }^{5}$ Our approach has several advantages over the more traditional country-level analysis. First and foremost, the use of industry-level data makes it possible to estimate the individual channels for the relationship between trade and volatility, something that has not been done before in the literature. Second, the three-dimensional panel makes it possible to include a much richer array of fixed effects in order to control for many possible unobservables and resolve most of the omitted variables and simultaneity concerns in estimation. In addition to country, sector, and time effects, we can control for time-varying sector or country characteristics, or characteristics of individual country-sector pairs. Third, besides looking at the volatility of GDP per capita (the standard measure used in previous studies), we can also look at other outcome variables, such as quantity, price, number of firms, output per firm, and employment at the industry level to further check robustness.

This paper is part of a growing literature that studies the determinants of volatility, and its subcomponents, using industry-level data. Most papers, however, focus on the determinants of one of the mechanisms we consider. For instance, Imbs and Wacziarg (2003) and Kalemli-Ozcan, Sørensen and Yosha (2003) explore the patterns of specialization, while Raddatz (2006) and Imbs (2006) study sector-level volatility. Krebs, Krishna and Mahoney (2005) use Mexican data at the individual level and examine the impact of trade liberalization on wage volatility and its welfare consequences. Buch, Döpke and Strotmann (2006) examine the link between export openness and volatility at the firm level using German data. Koren and Tenreyro (2007) use industry-level data to provide a decomposition of aggregate volatility into several subcomponents, and describe how they vary over the development process. The purpose of our paper is to analyze the relationship between trade and volatility, rather than to decompose volatility per se. In addition, we control for a country's level of development in various ways. To summarize, our paper is unique in its emphasis on trade and its use of trade data along with production. Thus, its contribution is in the comprehensive empirical exploration of multiple channels of the trade-volatility link.

\footnotetext{
5 The UNIDO database does not contain information on non-manufacturing sectors. Unfortunately, this limitation most likely leads to an understatement of the impact of openness on volatility for those countries that rely heavily on commodity exports, and are thus more vulnerable to global price shocks (Kose 2001). On the other hand, by examining the manufacturing sector alone we are able to focus on a sector that is generally considered key to a country's development process.
} 
The rest of the paper is organized as follows. Section II describes the empirical strategy and the data. Section III presents the regression results, while section IV discusses what these imply about the impact of the three channels on aggregate volatility. Section V concludes.

\section{EMPirical Strategy AND DATA}

\section{A. Empirical Strategy}

In an economy comprised of $\mathcal{I}$ sectors, the volatility of aggregate output growth $\sigma_{A}^{2}$ can be written as follows:

$$
\sigma_{A}^{2}=\sum_{i=1}^{\mathcal{I}} a_{i}^{2} \sigma_{i}^{2}+\sum_{i=1}^{\mathcal{I}} \sum_{\substack{j=1 \\ j \neq i}}^{\mathcal{I}} a_{i} a_{j} \sigma_{i j}
$$

where $a_{i}$ is the share of sector $i$ in total output, $\sigma_{i}^{2}$ is the variance of output growth in sector $i$, and $\sigma_{i j}$ is the covariance between sectors $i$ and $j$. Trade can be related to overall volatility through the variance of each sector separately $\left(\sigma_{i}^{2}\right)$, through the covariance properties between the sectors $\left(\sigma_{i j}\right)$, or through the production structure of the economy $\left(a_{i}\right)$. This paper analyzes each of these mechanisms in turn.

In particular, using the sector-level panel dataset on production and trade, it is straightforward to estimate the relationship between trade in a sector and the volatility of output in that sector, $\sigma_{i}^{2}$. We call this the Sector Volatility Effect. The main empirical specification is:

$$
\text { Volatility }_{i c t}=\alpha_{0}+\alpha_{1} \text { Output }_{i c t}+\beta_{\sigma} \text { Trade }_{i c t}+\mathbf{u}+\varepsilon_{i c t},
$$

where $i$ denotes sector, $c$ denotes country, and $t$ denotes time. The left-hand side, Volatility ${ }_{i c t}$, is the log variance of the annual growth rate of output per worker. ${ }^{6}$ In the cross-sectional specifications, the variance is computed over the entire sample period, 1970-99. In panel specifications, the volatility is computed over non-overlapping ten year periods: 1970-79, 1980-89, 1990-99. Trade $i c t$ is imports plus exports divided by output within a sector. The openness measure is the average for the same time periods over which the left-hand side variables are computed and is always in logs. The log of the beginning-of-period output per worker, Output ${ }_{i c t}$, controls for sector-specific, time-varying productivity. We experiment with various configurations of fixed effects $\mathbf{u}$. The cross-sectional specifications include both country and sector fixed effects. The panel specifications include country $\times$ sector fixed effects, country $\times$ time fixed effects, and sector $\times$ time fixed effects in alternative specifications.

To analyze the second effect, rewrite equation (1) as:

$$
\sigma_{A}^{2}=\sum_{i=1}^{\mathcal{I}} a_{i}^{2} \sigma_{i}^{2}+\sum_{i=1}^{\mathcal{I}} a_{i}\left(1-a_{i}\right) \rho_{i, A-i} \sigma_{i} \sigma_{A-i}
$$

\footnotetext{
${ }^{6}$ The results were fully robust when using the level of volatility on the left-hand side. We choose the log specifications whenever possible to reduce the impact of outliers and restrictions placed on the distribution underlying the errors.
} 
where the subscript $A-i$ is used to denote the sum of all the sectors in the economy except $i$. Thus, $\rho_{i, A-i}$ is the correlation coefficient of sector $i$ with the rest of the economy, and $\sigma_{A-i}$ is the standard deviation of the aggregate output growth excluding sector $i$. This way, rather than writing the aggregate variance as a double sum of all the covariances of individual sector pairs, equation (3) rewrites it as the sum of covariances of each sector $i$ with the rest of the economy. Note that aggregate variance can be expressed this way without any loss of generality.

The relationship between trade openness and the correlation between an individual sector and the rest of the economy, $\rho_{i, A-i}$, is the subject of the second empirical exercise. We call this the Comovement Effect. ${ }^{7}$ Just like $\sigma_{i}^{2}$, we calculate $\rho_{i, A-i}$ for each country, sector, and time period, and thus can estimate the relationship between trade openness and $\rho_{i, A-i}$ using industry-level data in the cross section and in ten-year panels:

$$
\text { Correlation }_{i c t}=\alpha_{0}+\alpha_{1} \text { Output }_{i c t}+\beta_{\rho} \text { Trade }_{i c t}+\mathbf{u}+\varepsilon_{i c t} .
$$

The right-hand side variables are the same as in the volatility specifications (see above). The left-hand side variable is the correlation of output per worker growth in sector $i$ with the overall manufacturing excluding that sector, $\rho_{i, A-i}$. In the cross-sectional specifications, these correlations are computed over thirty years. In the panel, we compute correlations over non-overlapping ten-year periods. ${ }^{8}$ In contrast to the volatility estimation in the previous section, the left-hand side is in levels rather than in logs because correlation coefficients can be negative. Note also that we use correlation rather than covariance. This is because the correlation coefficient is a pure measure of comovement, whereas changes in the covariance are influenced by changes in the sector-level variance. These are themselves affected by trade, as shown by the estimated impact of trade on sector-level volatility.

We next analyze whether trade is associated with increased specialization in a small number of sectors. Going back to equation (1), it is clear that aside from its effect on $\sigma_{i}^{2}$ 's and $\sigma_{i j}$ 's, trade openness can affect overall volatility through changing the configuration of $a_{i}$ 's. In particular, making the simplifying assumption that all sectors have the same $\sigma^{2}$, rewrite equation (1) as:

$$
\sigma_{A}^{2}=h \sigma^{2}+\sum_{i=1}^{\mathcal{I}} \sum_{\substack{j=1 \\ j \neq i}}^{\mathcal{I}} a_{i} a_{j} \sigma_{i j}
$$

where $h$ is the Herfindahl index of production shares in the economy. ${ }^{9}$ A higher value of $h$ represents a more specialized (less diversified) economy, and thus, at a given level of $\sigma^{2}$, leads

\footnotetext{
${ }^{7}$ Note that this effect is different from the cross-country comovement analyzed in the international business cycle literature (Backus, Kehoe and Kydland 1992, Frankel and Rose 1998, Baxter and Kouparitsas 2005, Burstein, Kurz and Tesar 2004, Kose and Yi 2006).

${ }^{8}$ We also estimated five-year panel specifications for both the volatility and correlation regressions. As the conclusions are remarkably similar to the ten-year panel specifications, we report only the cross-sectional and ten-year panel results to conserve space.

9 The Herfindahl index is defined as the sum of squared shares of each sector in total production: $h=\sum_{i} a_{i}^{2}$.
} 
to a higher aggregate volatility. We call this the Specialization Effect. We use industry-level production data to compute indices of specialization directly at the country level, and relate them to trade openness in the following empirical specification:

$$
\text { Specialization }_{c}=\alpha_{0}+\alpha_{1} \mathbf{X}_{c}+\beta_{h} \operatorname{Trade}_{c}+\varepsilon_{c} \text {. }
$$

Here, $c$ indexes countries, and the left-hand side variable is the log of the Herfindahl index of production shares of sectors in total manufacturing output, $h$, averaged over the sample period. ${ }^{10}$ Trade $_{c}$ is the log of total manufacturing trade divided by total manufacturing output. $\mathbf{X}_{c}$ are controls such as per capita GDP.

Note that the Specialization Effect estimates in this paper are reported for the cross-section of countries, rather than a panel with fixed effects. This is because in this sample of countries and years there is insufficient time series variation: the cross-sectional dispersion soaks up some $90 \%$ of the variation in these data. ${ }^{11}$ Thus, there is very little variation left to work with, especially in a cross-country setting with so few observations. For these reasons, the estimates in the paper rely on the cross-sectional sample to estimate the Specialization Effect.

\section{B. Additional Methodological Issues}

As mentioned above, we estimate the Sector Volatility and Comovement Effects in both cross-sectional and ten-year panel specifications. The advantage of the cross-sectional specifications is that the left-hand side variables - variances and correlations - are calculated over a long time series, reducing measurement error. The advantage of the panel specifications is that they make it possible to control for a much richer array of fixed effects.

In this context, it is worth discussing the issue of endogeneity. In our view, the main concern in this analysis is that there are factors affecting both openness in a sector and the volatility or comovement simultaneously. The major strength of our approach is the use of a variety of fixed effects to sweep out the vast majority of these concerns. In the cross section, country effects would control for any country characteristic that has not changed over the sample period, for instance any geographical or population features such as natural resources, climate, remoteness, colonial history, human capital, institutional quality, the legal system, the political system, and many others. Sector fixed effects would control for any inherent technological feature of industries, including, but not limited to, overall volatility, tradability, capital, skilled and unskilled labor intensity, R\&D intensity, tangibility, reliance on external finance, liquidity needs, or institutional intensity.

\footnotetext{
${ }^{10}$ There are gaps in the sector coverage in some countries and years. We only used country-years in which at least 20 sectors were available to calculate the Herfindahl. Varying this threshold does not affect the results. In addition, controlling for the number of sectors used to compute the Herfindahl in each country leaves the results unchanged.

${ }^{11}$ That is, the $\mathrm{R}^{2}$ in the regression of Herfindahl on country effects only is 0.9 in the panel of 10 -year averages.
} 
In the panel, the use of interacted fixed effects enables us to control for a much wider array of omitted variables. For example, country $\times$ time effects would absorb not just inherent country characteristics mentioned above, but also the average effect of time-varying country characteristics, such as overall level of development, growth, macroeconomic volatility, financial liberalization, any other reforms, episodes of political instability, monetary and fiscal policy changes, political regime changes, exchange rate regime changes, accession to WTO, any other trade blocks, currency unions, balance of payments/currency/banking crises, natural disasters, wars, and many others. Sector $\times$ time fixed effects will capture changes in sector characteristics over time across all countries, such as global growth opportunities and world demand and supply shocks. Finally, country $\times$ sector effects will capture the peculiar characteristics of each sector within each country that have not changed over the sample period 1970-99, such as the particular technological characteristics or sector-specific factor endowments varying at the country $\times$ sector level, or the importance of certain country $\times$ sectors, such as petroleum in Saudi Arabia or copper in Chile, for the national and global economy. Note that when country $\times$ sector fixed effects are included in the regressions, we are estimating how changes in trade openness over time relate to changes in volatility or comovement of that sector. That is, though we have a three-dimensional panel of countries and sectors, in that specification the identification comes purely from the time variation in the variables of interest within each sector in each country.

Including a plethora of fixed effects may still not resolve simultaneity problems at the country $\times$ sector $\times$ time level, however. We therefore reestimate the core specification adding a variety of controls and interaction terms. The list of variables includes terms-of-trade (TOT) volatility interacted with sector-level openness, the volatility of trade at the sector level, and a measure of financial development interacted with the Raddatz (2006) sector-level measure of liquidity needs. Another omitted variables concern has to do with the growth-volatility nexus. The macroeconomics literature finds a negative relationship between growth and volatility (Ramey and Ramey 1995), though recent work shows that at the sector level the opposite is true (Imbs 2006). In addition, faster growing sectors may also be more open to trade. Therefore, besides including initial output per worker as a proxy for growth potential in the baseline estimations, we also control for average levels and growth rates of output per worker as a further robustness check. Another concern is the role of sector size. For instance, it has been observed that larger sectors are less volatile. We control for this by including the size of the sector as an additional regressor. Finally, while in the main specifications the dependent variables are variances and correlations of output per worker growth, we also use a quantity index and a constructed sector-level price index to check robustness of the results.

Note that the most common approach in the literature has been to analyze the relationship between openness and volatility in a cross-country framework. The use of the sector-level data is in our view a step forward not only because it lets us investigate the individual channels as we do, but also because it allows us to overcome a vastly larger set of potential simultaneity problems. 
There still remains the possibility that openness and volatility or comovement are jointly determined in a two-way causal relationship. Our estimates could then be thought of as tracing out the equilibrium relationship between the variables. Even under such an interpretation, the findings in this paper are still informative and far from trivial. After all, any omitted variable or reverse causality mechanism could instead generate correlations between the variables of interest exactly opposite from what we find. Claims of endogeneity are difficult to evaluate in this case precisely because currently we do not have a good theoretical or empirical understanding of the nature of the causal interrelationships between these variables. This literature is in its infancy partly because even the basic features of the data have until now been largely unknown. This paper fills this gap.

However, in the meantime we would also like to make progress on the issue of causality. To do so requires an instrument for trade openness at the sector level. We follow the approach of Do and Levchenko (2007), which extends the methodology of Frankel and Romer (1999) to sector-level data. Frankel and Romer (1999) use the gravity model to predict bilateral trade volumes between each pair of countries based on a set of geographical variables such as bilateral distance, common border, area, and population. Summing up across trading partners then yields, for each country, its "natural openness": the overall trade to GDP as predicted by its geography.

Because we need an instrument for trade at sector level rather than total trade volumes, our point of departure is to estimate the Frankel and Romer gravity regressions for each industry. Following their methodology, we then obtain "sector-level natural openness": predicted trade volume as a share of output not just in each country, but also in each sector within each country. Appendix I lays out the details of this approach. Though the gravity right-hand side variables are all at country level and do not differ across sectors, the procedure generates variation in predicted openness across sectors within a country. The key is that the gravity coefficients differ across sectors. The approach exploits the fact that trade volumes respond differentially to geographical characteristics in different sectors - a common finding in the gravity literature. ${ }^{12}$ Note that this instrument is not available in a panel, because the gravity coefficients do not exhibit sufficient time variation. Thus, it can only be used in the cross-sectional specifications. Finally, to examine the Specialization Effect, we must rely on cross-country regressions because $h$ is measured at the country level. We therefore use original the Frankel and Romer (1999) measure of aggregate natural openness to instrument for trade, and also consider numerous controls previously suggested in the literature.

A recent paper by Koren and Tenreyro (2007) (henceforth KT) uses sector-level data to decompose aggregate volatility into several components, and analyze how these components change with the level of development. Our paper investigates a different question, examining

\footnotetext{
${ }^{12}$ See Appendix I for a detailed discussion of the overall instrumentation strategy, the relevant literature, as well as formal tests for coefficient heterogeneity.
} 
the relationship between trade openness and volatility instead. ${ }^{13}$ It is also important to emphasize that our results cannot be explained by KT's. To summarize briefly, KT find that poorer countries tend to specialize in fewer and more volatile sectors, and that poorer countries experience more severe macroeconomic (aggregate) shocks. KT's conclusions therefore suggest that we must control for the overall level of development in our regressions, as different aspects of macroeconomic volatility decline with per capita income. In the Sector Volatility and Comovement Effects estimates, this is accomplished by country and country $\times$ time effects. In the Specialization regressions, we control for the level of income, as well as the level of income squared, to pick up the potential U-shape between income and diversification.

Thus, it is clear that the results in this paper are not driven by the facts that KT uncover. On the flip side, do our results imply any of KT's results? There does not seem to be a clear relationship. Since the level of development is absorbed in our regressions, it appears that the impacts of trade and the overall level of development on macroeconomic volatility are each important independently. In other words, this paper and KT describe conceptually and empirically distinct relationships between different sets of variables, and neither is a subset of the other. At a more impressionistic level, it is also clear that the implications of the two papers are not that similar. We find that trade is on average accompanied by increased macroeconomic volatility. At the same time, KT find that as countries develop, volatility decreases. The two would seem to imply the opposite impacts on the evolution of macroeconomic volatility, if we believe that both incomes and trade openness went up on average in the past few decades.

\section{Data and Summary Statistics}

Data on industry-level production, quantity indices, employment, number of firms, and prices come from the 2006 UNIDO Industrial Statistics Database. We use the version that reports data according to the 3-digit ISIC Revision 2 classification for the period 1963-2003 in the best cases. There are 28 manufacturing sectors, plus the information on total manufacturing. We use data reported in current U.S. dollars, and convert them into constant international dollars using the Penn World Tables (Heston, Summers and Aten 2002). ${ }^{14}$ We also correct inconsistencies between the UNIDO data reported in U.S. dollars and domestic currency. We dropped observations that did not conform to the standard 3-digit ISIC classification, or took

\footnotetext{
${ }^{13}$ Relatedly, while both this paper and KT perform a decomposition, the meaning of the word is different in the two papers. While KT break down the level of aggregate volatility into several components, we quantify the relative importance of our three channels on the change in aggregate volatility associated with trade openness. Furthermore, while KT's methodology allows to calculate each subcomponent of volatility for each country, our goal of estimating the marginal effect of trade implies that we can only evaluate the relative importance of the three effects on the average across countries.

${ }^{14}$ Using the variable name conventions from the Penn World Tables, this deflation procedure involves multiplying the nominal U.S. dollar value by $(100 / P) *(R G D P L / C G D P)$ to obtain the constant international dollar value.
} 
on implausible values, such as a growth rate of more than $100 \%$ year to year. ${ }^{15}$ The resulting dataset is an unbalanced panel of 61 countries. We insure that for each country-year we have a minimum of 10 sectors, and that for each country, there are at least 10 years of data.

We combine information on sectoral production with international trade flows from the World Trade Database (Feenstra et al. 2005). This database contains bilateral trade flows between some 150 countries, accounting for $98 \%$ of world trade. Trade flows are reported using the 4-digit SITC Revision 2 classification. We convert the trade flows from SITC to ISIC classification and merge them with production data. The final sample is for the period 1970-99, or three full decades.

Appendix Table A1 reports the list of countries in the sample, along with some basic descriptive statistics on the average growth rate of output per worker in the manufacturing sector, its standard deviation, its import penetration, and the share of output that is exported. The median growth rate of total manufacturing output per worker in this sample is $2.8 \%$, and the median standard deviation is $7 \%$. There is some dispersion in the average growth rates of the manufacturing output per worker, with Honduras at the bottom with a mean growth rate of $-5.2 \%$ per year over this period, and Pakistan at the top with $6.2 \%$ per year. There are also differences in volatility, with the United States having the least volatile manufacturing sector, and Malawi the most. Import penetration and the share of total manufacturing production that gets exported vary a great deal across countries. Appendix Table A2 lists the sectors used in the analysis, along with similar descriptive statistics. Average growth rates of output per worker across sectors range from roughly $2 \%$ per year for leather products to $6 \%$ for petroleum refineries. Individual sectors have much higher volatility than manufacturing as a whole, and differ among themselves as well. The least volatile sector, wearing apparel, has an average standard deviation of $11 \%$. The most volatile sector is petroleum refineries, with a standard deviation of $26 \%$.

Using these data, we can calculate the variance of the growth rate of total manufacturing output per worker, and compare it with the variance of per capita GDP growth from Penn World Tables. The scatterplot of that comparison, in logs, is presented in Figure 2, along with a linear regression line. There is a close relationship between the two, with the correlation coefficient of around 0.7 . The volatility of manufacturing output growth from the UNIDO dataset is considerably higher than the volatility of per capita GDP growth from Penn World Tables. This is sensible, because manufacturing output is a subset of GDP. Figure 3 reports a scatterplot of trade openness and volatility of the manufacturing sector for the countries in the sample, along with a regression line. There does seem to be a positive relationship between trade openness and volatility in the sample. We now move on to an in depth analysis of this relationship at the sector level.

\footnotetext{
15 The latter is meant to take out erroneous observations, such those arising from sector reclassifications. It results in the removal of less than $1 \%$ of yearly observations, and does not affect the results. The coarse level of aggregation into 28 sectors (e.g. Food Products, Apparel, and Electrical Machinery) makes is highly unlikely that a sector experiences a genuine takeoff of doubling production from year to year.
} 


\section{RESUlTS}

The results can be summarized as follows. Trade openness is associated with (i) higher sector-level volatility; (ii) lower comovement of a sector with the rest of the manufacturing sector; and (iii) higher specialization. These results are robust across both cross-sectional and panel estimations, to the battery of fixed effects and controls that we use to deal with omitted variables and simultaneity issues, and an instrumental variables approach.

\section{A. Trade and Volatility within a Sector}

We first analyze the relationship between trade and the volatility of output within a sector, $\sigma_{i}^{2}$, by estimating equation (2). Table 1 presents the cross-sectional results. The first column reports the results of the most basic regression, while columns (2) through (4) add progressively more fixed effects. Overall trade openness, measured as the share of exports plus imports to total output in a sector, is always positively related to volatility. This result is robust to the inclusion of any fixed effects and is statistically significant, with $t$-statistics in the range of 5-10. The point estimates are also quite stable across specifications.

The last two columns present the two-stage least squares estimates using the gravity-based instrument for trade at the sector level described in Section B and Appendix I. As detailed in the Appendix, we use two variations on the instrument: (i) based on the in-sample prediction; and (ii) based on the pseudo-maximum likelihood estimates suggested by Santos Silva and Tenreyro (2006). Columns (5) and (6) report the results. The point estimates do not differ greatly compared to the OLS, though they are less significant. The first stage is highly significant, with the partial $R^{2}$ 's between 0.08 and 0.1 , and the $F$-statistics for the instrument between 50 and 100, indicating that the instrument is not weak (Stock and Yogo 2005).

Table 2 reports estimation results for the ten-year panel regressions. All panel estimation results in this paper are reported with standard errors clustered at the country $\times$ sector level, to correct for possible serial correlation in the error term. We include specifications with no fixed effects, country, sector, time effects separately and together, and then interacted with each other. The most stringent possible specification, in terms of degrees of freedom, includes country $\times$ sector, sector $\times$ time, and country $\times$ time fixed effects. The coefficients on trade openness are actually quite stable across specifications, and always statistically significant. Overall, the cross-sectional and panel results yield remarkably similar conclusions.

The link between trade and volatility, while highly significant, is not implausibly large quantitatively. In particular, a one standard deviation increase in the right-hand side trade variable, the log of exports plus imports to output, is associated with an increase in the log variance of output per worker growth of between 0.15 and 0.25 standard deviations, depending on the coefficient estimate used.

Appendix Tables A3 and A4 present a slew of robustness checks using a variety of different controls and interaction terms. The coefficient of interest remains positive and significant at 
the $1 \%$ level across all specifications, and the point estimates do not vary dramatically relative to the baseline estimates in Tables 1 and 2. First, turning to columns (1) and (2) in Table A3, using either average productivity or average growth rates instead of initial output per worker does not alter the results. As discussed above, both of these variables are positively related to volatility at the sector level, as reported in Imbs (2006). Column (3) instead controls for sector size by including the share of the sector in total output as an additional control. The results are robust. Column (4) drops country effects, and uses the volatility of a country's terms of trade (TOT) instead. Terms-of-trade data are obtained from the Penn World Tables. TOT volatility is indeed positively related to volatility of production, but trade openness itself remains significant. The TOT volatility on its own was controlled for in the baseline regressions by country and country $\times$ time effects. However, it could be that TOT volatility affects more open sectors disproportionately, and this effect is driving the results. Column (5) interacts the country-level TOT volatility with total trade in a sector while including country fixed effects, which is a more general specification than including TOT volatility on its own. The main result is not affected; in fact, the coefficient on this interaction is insignificant. It could also be that what really matters is not the average trade openness in a sector, but the volatility of trade in that sector. To see if this is the case, Column (6) controls for the sector-level volatility of trade. It turns out that the coefficient on the volatility of trade is not significant, providing further confidence that simultaneity is not a major issue. ${ }^{16}$ Interacting the level of trade with its volatility in Column (7) also leaves the main result unchanged. Column (8) uses another country-level variable, the share of manufacturing trade to total trade, instead of country effects. This share is negatively related to the volatility of production, which may simply reflect that the share is greater for industrial countries, which experience less volatility on average. ${ }^{17}$ Raddatz (2006) studies volatility at the sector level using a version of the UNIDO database, and finds that financial development matters more in industries with higher liquidity needs. Column (9) includes the interaction of the Raddatz liquidity needs measure with a country's financial development, where the latter is proxied by private credit as a share of GDP coming from the Beck, Demirgüç-Kunt and Levine (2000) database. The coefficient on trade openness remains significant at the $1 \%$ level. The negative coefficient on the interaction term in column (9) corresponds to Raddatz (2006). ${ }^{18}$ Appendix Table A4 repeats these robustness checks in the panel specifications, and reaches the same conclusion.

\section{Sector-Level Volatility in Price and Quantity per Worker}

In addition to total output and employment, the UNIDO database also reports sector-level quantity indices. It is therefore possible to construct annual growth rates of the quantity of output per worker for each sector, and calculate the same volatility measure as we did for

\footnotetext{
16 The results were similar when using the volatility of a sector's trade-to-output ratio instead of total trade.

17 We also interacted this variable with sector-level trade. The results were unchanged.

18 We also interacted Raddatz's measure with country fixed effects, and the results were unchanged. Note that doing so is a more general specification than using the interaction with financial development.
} 
output per worker. ${ }^{19}$ Furthermore, given that output per worker equals price times quantity per worker, it follows that we can back out the growth rate of the sector-specific price index by subtracting the growth rate of quantity per worker from the growth rate of output per worker. ${ }^{20}$ We then calculate the volatility measures for the sector-specific price index.

This rough separation of the growth rates of output per worker into the growth rate of quantity and of price does not help identify the channels through which trade openness affects volatility. Indeed, no matter what the shock, one would expect both the price and the quantity to move. Nonetheless, examining the effect of trade on quantities and prices serves as a further robustness check on the results, by showing that trade affects the volatility of both. Table 3 presents the baseline volatility regressions for quantity per worker and price. The openness coefficient is positive and significant for both left-hand side variables across all specifications. $^{21}$

\section{Sector-Level Volatility in Number of Firms and Output per Firm}

The UNIDO database also reports the number of firms in each sector. This variable makes it possible to get a glimpse at two possible channels underlying the trade-volatility link. In particular, trade openness could be positively related to volatility through higher entry and exit of firms (i.e., the extensive margin), through volatility in the output of existing firms (i.e. the intensive margin), or both. Therefore, we compute two measures. The first is the volatility of the annual growth rate in number of firms, and the second is the volatility in the growth rate of output per firm. The former is meant to shed light on the extensive margin, that is, entry and exit of firm, and the latter on the intensive margin, the output volatility of a typical firm. ${ }^{22}$ Table 4 reports the results for the volatility in the number of firms and output per firm. The openness coefficient is positive and significant for both left-hand side variables across all

\footnotetext{
${ }^{19}$ Another quantity-based measure we used to check for robustness is simply the growth rate of employment. The effect of trade on the volatility of employment is equally significant as its effect on the headline measure, output per worker. The full set of results is available upon request.

${ }^{20}$ Namely, if OUTPUT $i c t$ is nominal output, and INDPROD $i c t$ is the index number of industrial production, then the sector-specific growth rate of prices is GrowthP $_{i c t}=\log \left(\left(\right.\right.$ OUTPUT $_{i c t} /$ OUTPUT $\left._{i c(t-1)}\right) /\left(\right.$ INDPROD $\left.\left._{i c t} / \operatorname{INDPROD}_{i c(t-1)}\right)\right)$.

${ }^{21}$ Panel estimates are similar to the cross-sectional ones, and are thus omitted to conserve space. They are available from the authors upon request.

22 However, it is also important to emphasize the limitations of this exercise. First, UNIDO only reports the total number of firms in each year, and not gross entry and exit. Therefore, is it only possible to calculate the volatility of the net change in the number of firms. By contrast, it could be that as a result of greater trade openness, both gross entry and gross exit increase dramatically. However, the available data in UNIDO will not pick that up. The second limitation is that is no information on the characteristics of firms (e.g., size, age, productivity) that are entering and/or exiting. Thus, these data cannot be used for a precise test of trade models with heterogeneous firms.
} 
specifications except for three of the IV regressions. ${ }^{23}$ Thus, the data are broadly consistent with both the extensive and the intensive margin hypotheses.

\section{B. Trade and Sector Comovement}

We next estimate equation (4), the relationship between trade and the correlation of a sector's output growth with the rest of the manufacturing sector $\left(\rho_{i, A-i}\right)$. Table 5 presents the cross-sectional results. Intriguingly, more trade in a sector comes with a reduced correlation of that sector with the rest of the economy. This negative relationship is robust across specifications, although the significance level is typically not as high as in the volatility regressions, and the magnitude of coefficients not as stable. It is clear that increased exposure to the world cycle for a sector decouples it from the domestic economy. This comovement effect acts to reduce the overall variance in the economy, ceteris paribus. The last two columns of Table 5 report the IV results, which are weaker than the OLS results. While the coefficient of interest is negative, it is only significant for one of the two versions of the instrument.

Table 6 presents results for the ten-year panel estimation. The results are broadly in line with those of the cross section, and robust to almost the entire battery of fixed effects. The only exception is the most stringent possible set of fixed effects, which includes the country $\times$ sector, country $\times$ time, and sector $\times$ time effects simultaneously. The coefficient of interest is still negative, but no longer significant. Overall, the relationship between trade and comovement is economically significant, and plausible in magnitude. A one standard deviation increase in the overall trade is associated with a decrease in correlation of between 0.07 and 0.17 standard deviations, depending on the coefficient estimate used.

Table 7 presents the baseline correlation specifications on the price and quantity per worker variables separately. ${ }^{24}$ The OLS coefficients are all negative and significant. Note that the IV results are more robust for the price and quantity variables than for the output per worker volatility. Though the comovement effect is less robust to the IV strategy, one could argue that reverse causality arguments are more difficult to make in the case of the comovement effect. There are currently no models of the causal effect of comovement with aggregate growth on trade openness.

Appendix Tables A5 and A6 present numerous robustness checks using a variety of different controls and interaction terms. The openness coefficient remains negative and significant across all specifications, and the point estimates do not vary dramatically relative to the baseline estimates in Tables 5 and 6 . All of the panel specifications include country $\times$ sector and time effects, and thus identify the relationship purely from the time series variation within

\footnotetext{
${ }^{23}$ Panel estimates are similar to the cross-sectional ones, and are thus omitted to conserve space. They are available from the authors upon request.

${ }^{24}$ Panel estimates are similar to the cross-sectional ones, and are available from the authors upon request.
} 
each sector in each country. The properties of sector-level correlation with the aggregate growth have not been previously studied in the literature. Therefore, it is much less clear than in the case of sector-level volatility which additional controls it is important to include alongside the fixed effects. The approach here is to use the same battery of robustness checks as those employed in the sector volatility regressions. We control for average level and growth rate of output, sector size, TOT volatility (both as main effect and interacted with sector-level trade), sector-level volatility of trade, share of manufacturing trade in total trade, and Raddatz's interaction of liquidity needs and financial development. Since these were used above, we do not discuss them in detail. The coefficient of interest is robust to all of the alternative specifications.

\section{Trade and Specialization}

Finally, we estimate the relationship between trade and specialization $(h)$, equation (6). Table 8 reports the results. Column (1) is the bivariate OLS regression of trade openness on the Herfindahl index, while column (2) controls for log per capita PPP-adjusted GDP from Penn World Tables. The coefficient on trade is significant at the $1 \%$ level. Since trade openness is likely endogenous to diversification, columns (3) and (4) repeat the exercise instrumenting for trade using natural openness from Frankel and Romer (1999). Results are unchanged, and the magnitude of the coefficient is not affected dramatically. In order to probe further into this finding, columns (5) and (6) control directly for how the export patterns are related to industrial specialization. We construct the Herfindahl index of export shares in a manner identical to our index of production concentration. The coefficient on trade openness decreases, but remains significant at the $1 \%$ level. The coefficient on the Herfindahl of export shares is highly significant as well.

Figure 4 illustrates these results. It presents partial correlations between trade openness and the Herfindahl index of sector shares for the available countries, once per capita income has been netted out. It is clear that there is a positive relationship between trade and specialization. The effect of trade openness and export concentration on the specialization of production is sizeable. A one standard deviation change in log trade openness is associated with a change in the log Herfindahl of production equivalent to about 0.54 of a standard deviation. A one standard deviation change in export specialization is associated with a change in the log Herfindahl of production of roughly 0.68 standard deviations.

Appendix Table A7 presents further robustness checks. All of the specifications in that table include per capita income and the Herfindahl of exports as controls, and are estimated using IV unless otherwise indicated. ${ }^{25}$ Column (1) checks whether the results are driven by outliers. Dropping outliers improves the fit of the regression, and the results remain significant. Columns (2) and (3) check that the results are robust to an alternative measure of trade openness. We use total trade openness as a share of GDP from the Penn World Tables instead of total manufacturing trade as a share of manufacturing output from our data. It is clear that

\footnotetext{
${ }^{25}$ The corresponding OLS results (not reported) are significant in every case as well.
} 
the main result is not driven by our particular measure of trade openness: both OLS and IV coefficients are robustly significant. We next control for other potential geographic determinants of specialization. Column (4) includes distance to equator and shares of agriculture and mining in GDP. Column (5) adds more geographic controls, such as a percentage of land area in the tropics, mean temperature, and the average number of days of frost. $^{26}$ Those coefficients are not significant and are not reported to conserve space. Column (6) adds region dummies. ${ }^{27}$ Finally, the specification in column (7) is based on the work of Kalemli-Ozcan et al. (2003), and includes a wide variety of additional controls, such as income risk sharing, population density, population, and distantness. ${ }^{28}$ In addition, we follow Imbs and Wacziarg (2003) and include GDP per capita and its square to capture the U-shaped pattern of diversification over the development process. The results are robust to this specification.

\section{The Impact on Aggregate Volatility}

The preceding section estimated the relationship between trade and the variance of individual sectors $\left(\sigma_{i}^{2}\right)$, the correlation coefficient between an individual sector and the rest of the economy $\left(\rho_{i, A-i}\right)$, and the Herfindahl index of sectoral concentration of production shares $(h)$. This section uses these estimates to quantify the impact of each of the three effects on aggregate volatility, as well as their combined impact.

We do this in a number of ways. The first exercise calculates the effect of moving from the $25^{\text {th }}$ to the $75^{\text {th }}$ percentile in the distribution of trade openness observed in the sample. It is meant to capture mainly the consequences of cross-sectional variation in trade across countries. The second exercise considers the average increase in trade openness in the sample over time, from the 1970s to the 1990s, and uses it to calculate the expected impact of this trade expansion on aggregate volatility, through each channel as well as combined. Third, we calculate how the estimated impact of trade openness on aggregate volatility differs across countries based on observed characteristics of these countries. The final exercise examines how the nature of the relationship between trade and volatility has changed over time. To do so, we reestimate the three sets of equations from the previous section by decade, and use the decade-specific coefficients to calculate the impact of trade on aggregate volatility for each decade.

\footnotetext{
26 These data come from Harvard's Center for International Development.

27 The regions are East Asia and Pacific, Europe and Central Asia, Latin America and the Caribbean, Middle East and North Africa, North America, South Asia, and Sub-Saharan Africa.

28 The measure of income risk sharing is in the spirit of Kalemli-Ozcan et al. (2003) and comes from Volosovych (2006). It is constructed as the coefficient in the regression of the growth rate of GDP minus the growth rate in the national income on the growth rate of GDP, in which all variables are expressed in deviations from world averages. Intuitively, it captures the share of the idiosyncratic country shock that a country can insure internationally. Distantness is the GDP-weighted distance to all of the country's potential trading partners.
} 
These exercises are straightforward extensions of a common one performed in most empirical studies, which asks "what is the effect of a one standard deviation change in the right-hand side variable of interest on the left-hand side variable?" This calculation was carried out after each set of regressions separately, but in this case it is also important to compare the relative magnitudes of these three effects, and estimate the average impact of each channel on aggregate volatility. We do this using a Taylor expansion to relate sector-level changes to aggregate ones and separate the effects of each channel on aggregate volatility. This requires some simplifying assumptions, discussed below. It turns out that these assumptions do not appreciably affect the main conclusion about the average impact of the three channels on aggregate volatility in this sample of countries.

\section{A. The Relationship between Each Channel and the Aggregate Volatility}

The aggregate variance, $\sigma_{A}^{2}$, can be written as a function of $\sigma_{i}^{2}$ and $\rho_{i, A-i}$ as in equation (3), reproduced here:

$$
\sigma_{A}^{2}=\sum_{i=1}^{\mathcal{I}} a_{i}^{2} \sigma_{i}^{2}+\sum_{i=1}^{\mathcal{I}} a_{i}\left(1-a_{i}\right) \rho_{i, A-i} \sigma_{i} \sigma_{A-i}
$$

In order to evaluate the estimated effect of trade-induced changes in $\sigma_{i}^{2}, \rho_{i, A-i}$, and $h$, assume for simplicity that for all sectors, the variances and correlations are equal: $\sigma_{i}^{2}=\sigma^{2}, \rho_{i, A-i}=\rho$, and $\sigma_{A-i}=\sigma_{A-}$ for all $i$. Equation (7) can then be written in terms of $\sigma^{2}, \rho$, and $h$ as:

$$
\sigma_{A}^{2}=h \sigma^{2}+(1-h) \rho \sigma \sigma_{A-} .
$$

Using a Taylor approximation, the effect of changes in the three variables $\left(\Delta \sigma^{2}, \Delta \rho\right.$, and $\left.\Delta h\right)$ on the aggregate volatility is:

$$
\Delta \sigma_{A}^{2} \approx \frac{\partial \sigma_{A}^{2}}{\partial \sigma^{2}} \Delta \sigma^{2}+\frac{\partial \sigma_{A}^{2}}{\partial \rho} \Delta \rho+\frac{\partial \sigma_{A}^{2}}{\partial h} \Delta h
$$

We can compute the partial derivatives using equation (8):

$$
\Delta \sigma_{A}^{2} \approx \underbrace{\left(h+(1-h) \rho \frac{\sigma_{A-}}{2 \sigma}\right) \Delta \sigma^{2}}_{\text {[1] Sector Volatility Effect }}+\underbrace{(1-h) \sigma \sigma_{A-} \Delta \rho}_{\text {[2] Comovement Effect }}+\underbrace{\left(\sigma^{2}-\rho \sigma \sigma_{A-}\right) \Delta h}_{\text {[3] Specialization Effect }} .
$$

Each term represents the partial effect of the three channels on the aggregate volatility, and their sum is the combined impact.

The values of $\Delta \sigma^{2}, \Delta \rho$, and $\Delta h$ as a function of changes in openness come from the estimated equations:

$$
\begin{aligned}
\Delta \sigma^{2} & =\widehat{\beta}_{\sigma} \sigma^{2} \Delta \log (\text { Openness }) \\
\Delta \rho & =\widehat{\beta}_{\rho} \Delta \log (\text { Openness }) \\
\Delta h & =\widehat{\beta}_{h} h \Delta \log (\text { Openness })
\end{aligned}
$$


where $\widehat{\beta}_{\sigma}$ is the coefficient on the trade openness variable in equation (2), $\widehat{\beta}_{\rho}$ is the coefficient on trade openness obtained from estimating equation (4), and $\widehat{\beta}_{h}$ comes from estimating the specialization equation (6). ${ }^{29}$ The various exercises performed in this section differ only in the kinds of values plugged in for $\Delta \log ($ Openness $), \sigma^{2}, \rho, h, \sigma_{A-}, \widehat{\beta}_{\sigma}, \widehat{\beta}_{\rho}$, and $\widehat{\beta}_{h}{ }^{30}$

It is important to emphasize that this paper does not provide a decomposition of the effects of trade on volatility for each individual country. This would not be feasible in a regression-based approach. Instead, the estimates in this section come from a counterfactual thought experiment in which trade openness increases by a given amount holding other country and sector characteristics constant. Thus, these estimates are intended to reflect the average impact of trade through these three channels across countries in the sample.

In this context, how restrictive is the assumption of symmetry in $\sigma, \rho$, and $\sigma_{A-}$ across sectors, used to simplify equation (7) to equation (8)? Appendix II offers a detailed treatment of this question. The main result is that while (8) may not be a good approximation for the actual aggregate variance in every country, on average in this sample it is a good approximation for $\sigma_{A}^{2}$. Consequently, equation (8) produces a reliable estimate of the average impact the Sector Volatility and Comovement Effects in this sample of countries. What is required is the assumption that the change in trade openness is the same across sectors. That is, the thought experiment in this calculation is that of a symmetric increase in trade openness across all sectors. This assumption follows most naturally from the regression-based approach of this paper, which estimates the average effect of the level of trade openness across countries and sectors. ${ }^{31}$ For calculating the Specialization Effect, the symmetry assumption is necessary, and could ignore important country-specific information. For instance, a given country may come to specialize systematically in more (less) risky sectors. We cannot capture such effects in this paper through comparative statics on $h$. A companion paper (di Giovanni and Levchenko 2007) is entirely devoted to this subject, and can thus serve to complement the calculations here. However, Appendix II shows that while specialization in especially risky or safe sectors may be important for individual countries, equation (8) provides on average a good approximation for the aggregate variance across countries.

Finally, we must mention an additional point regarding aggregation. Our exercise considers the impact of an overall increase in trade openness in a country, across all industries. Meanwhile, the empirical specifications estimated in this paper, (2) and (4), assume that volatility and comovement in a sector are affected by the trade openness only in that sector.

\footnotetext{
${ }^{29}$ Note that in the estimation equations (2) and (6), the left-hand-side variable is in logs. Hence, in order to get the change in its level in equations (11) and (13), we must multiply the estimated coefficients by the average level of the variable.

${ }^{30}$ The baseline calculations apply the values of $\widehat{\beta}_{\sigma}, \widehat{\beta}_{\rho}$, and $\widehat{\beta}_{h}$ from columns (4) in Tables 2, 5, and 8 respectively.

${ }^{31}$ Note that the use of country fixed effects in estimation does not preclude us from running this counterfactual thought experiment. On the contrary, they are necessary in order to control for omitted variables that vary at country level and could affect both sector-level volatility and trade openness.
} 
As such, the aggregation exercise could be missing the total impact of an increase in overall trade openness if there is an independent effect of trade openness in some sectors on volatility or comovement of other sectors. To ascertain whether or not this is the case, we carried out supplementary estimation allowing trade in the rest of the economy except sector $i$, Trade $_{A-i, c t}$, to affect volatility and comovement in sector $i$. The results show that there is no robust independent effect of aggregate trade outside of sector $i$ on volatility or comovement in sector $i$. In addition, the estimated coefficients on the within-sector openness are virtually unchanged relative to our baseline results. However, the coefficient on Trade ${ }_{A-i, c t}$ is highly unstable across specifications, an indication that the omitted variables problem looms large for this variable. ${ }^{32}$ Thus, while the evidence suggests that the aggregation procedure described above is indeed informative, it must be kept in mind that it is based on a model in which volatility and comovement in a sector are affected only by trade within the sector.

\section{B. The Impact Across Countries and Over Time}

The first two exercises use the average values of $\sigma^{2}, \rho$, and $h$ found in the sample. These are reported in the first row of Table T1. The average Herfindahl index in our sample is $h=0.12$. The average comovement of a sector with the aggregate is $\rho=0.34$, while the average variance of a sector is $\sigma^{2}=0.038$. For the variance of the entire economy minus one sector, $\sigma_{A-}^{2}$, we simply use the average aggregate volatility in our sample of countries, which is 0.008 . This turns out to be a very good approximation of the volatility of all the sectors except one, since the mean share of an individual sector in total manufacturing is just under 0.038 , and thus on average, subtracting an individual sector from the aggregate does not make much difference.

The dispersion in the overall manufacturing trade as a share of output in the sample implies that moving from the $25^{\text {th }}$ to the $75^{\text {th }}$ percentile in overall trade openness is equivalent to an increase in total trade to manufacturing output of about 60 percentage points (or moving from the manufacturing trade openness of the United Kingdom to that of Indonesia). This change in overall trade is associated with a change in sector-level variance of $\Delta \sigma^{2}=0.0046$. From equation (10), it follows that this increase in sector-level volatility raises aggregate volatility by 0.0009 , which is of course considerably smaller than the sector-level increase, due to diversification among sectors. This change is sizeable, however, relative to the observed magnitudes of aggregate volatility. In particular, it is equivalent to about $10.2 \%$ of the average aggregate variance found in our data.

Moving on to the Comovement Effect, the regression estimates indicate that the same increase in trade comes with a reduction of correlation between the sector and the aggregate equal to $\Delta \rho=-0.034$. Plugging this into equation (10) and evaluating the partial derivative, the reduction in the aggregate variance due to decreased comovement is equal to -0.0005 . This amounts to a reduction equivalent to $6.3 \%$ of the mean aggregate variance observed in the data. Finally, according to the estimates, the change in overall trade openness equivalent to

\footnotetext{
${ }^{32}$ Implementation details and results are available upon request from the authors.
} 
Table T1. Summary Statistics Used in Magnitude Calculations

\begin{tabular}{|c|c|c|c|c|}
\hline Sample & $\overline{\sigma_{i}^{2}}$ & $\rho_{i, A-i}$ & $h$ & $\overline{\overline{\sigma_{A-}^{2}}}$ \\
\hline Full & 0.038 & 0.335 & 0.117 & 0.008 \\
\hline Developed & 0.014 & 0.415 & 0.095 & 0.003 \\
\hline Developing & 0.051 & 0.292 & 0.129 & 0.011 \\
\hline $1970 \mathrm{~s}$ & 0.039 & 0.366 & 0.115 & 0.011 \\
\hline $1980 \mathrm{~s}$ & 0.038 & 0.326 & 0.109 & 0.008 \\
\hline $1990 \mathrm{~s}$ & 0.039 & 0.320 & 0.119 & 0.007 \\
\hline
\end{tabular}

Notes: This table reports the averages of the variables used to calculate the three effects in equation (10) for the full sample and the various subsamples. $\sigma^{2}$ is the average sector-level volatility, $\rho$ is the average correlation coefficient between an individual sector and the aggregate less that sector, $h$ is the average Herfindahl index, and $\sigma_{A-}^{2}$ is the average volatility of the aggregate minus one sector, which is approximated by the aggregate volatility.

moving from the $25^{\text {th }}$ to the $75^{\text {th }}$ percentile is associated with a change in the Herfindahl index of $\Delta h=0.036$. The resulting change in aggregate volatility from this increased specialization is $\Delta \sigma_{A}^{2}=0.0011$. Thus, increased specialization raises aggregate volatility by about $13.5 \%$ of its mean.

These calculations, summarized in the first two rows of Table 10, imply changes in aggregate volatility related to trade that are relatively modest and plausible in magnitude. Two of the effects imply increased volatility, while the other leads to a reduction. Adding up the three effects, the overall change in aggregate volatility as implied by equation (10) is $\Delta \sigma_{A}^{2} \approx 0.0015$, or about $17.3 \%$ of average variance of the manufacturing sector observed in the data over the sample period, 1970-99. The table also reports, for each calculation, the standard error associated with the use of the point estimates for the $\beta$ 's.

The previous exercise was informative of the kind of differences in aggregate volatility one can expect from the dispersion of trade openness found in the cross section. That is, we computed the expected differences in volatility as a function of differences in trade openness across countries. Alternatively, we can ask how the increase in trade over time within the sample period is expected to affect aggregate volatility. To learn this, we calculate the mean difference in the total trade to manufacturing output between the 1970s and the 1990s in the sample. It turns out that trade openness increased by about 30 percentage points over the period, going from below 60 percent in the 1970s to almost 90 percent in the 1990s. The change in trade openness of this magnitude implies an estimated increase in aggregate 
volatility of roughly 0.0007 . Since this calculation uses the same mean values of $\sigma^{2}, \rho, h$, $\sigma_{A-}$, and the same $\widehat{\beta}_{\sigma}, \widehat{\beta}_{\rho}$, and $\widehat{\beta}_{h}$, the relative importance of the three effects is the same as in the first exercise: the sectoral volatility effect raises aggregate volatility by about 0.0004 , the comovement effect lowers it by -0.00025 , and the specialization effect raises it by about $0.00053 .^{33}$

How sizeable is this effect? Relative to what is observed in the cross section, this implied change in volatility is equivalent to 8 percent of the average aggregate variance in the sample. Alternatively, it can also be compared to the changes in aggregate volatility that occurred between the 1970s and the 1990s. It turns out that on average, aggregate volatility has decreased by 0.0037 over this period. By this metric, the implied increase in volatility of 0.0007 associated with growing trade is equivalent to almost one fifth of the observed decrease in aggregate volatility. Trade has therefore counteracted the general tendency of the smoothing out of business cycles over time. ${ }^{34}$

\section{Country Characteristics and the Impact on Aggregate Volatility}

The two calculations above imply that the trade-related change in aggregate volatility acting through the three channels is appreciable but modest. However, these are based on sample averages of $\sigma^{2}, \rho, h$, and $\sigma_{A-}$, and clearly the estimated impact of trade will differ depending on these country characteristics. For instance, the sectoral volatility effect would be significantly less important in a highly diversified economy (low $h$ ), while the comovement effect will be magnified in a country with a high volatility $\left(\sigma^{2}\right.$ and $\left.\sigma_{A_{-}}\right)$. Thus, it is important to get a sense of how the magnitudes change as these country characteristics vary.

We do this in two ways. First, we calculate the averages of $\sigma^{2}, \rho, h$, and $\sigma_{A-}$ for the developed and developing country subsamples, and use them to calculate the impact of trade on these two groups of countries. ${ }^{35}$ The subsample averages of $\sigma^{2}, \rho, h$, and $\sigma_{A-}$ are summarized in Table T1. Developing countries are considerably more volatile, somewhat less diversified, and have lower average comovement of sectors. Table 10 presents the comparison of the impact of trade in the developed and developing countries. These calculations keep the magnitude of the trade opening and the $\beta$ 's the same for both. ${ }^{36}$ The differences between the two groups are pronounced. It turns out that the same change in openness is associated with a

\footnotetext{
33 A caveat is in order for interpreting this calculation. Though the change in trade openness in this exercise is over time, the coefficients used to compute the estimated impact are based on the cross-sectional variation. In particular, as discussed above, the data do not exhibit enough within-country variation in the Herfindahl index over time to obtain fixed effects panel estimates of the Specialization Effect.

${ }^{34}$ See Stock and Watson (2003) for evidence on the fall in volatility in the U.S. and Cecchetti, Flores-Lagunes and Krause (2006) for cross-country evidence.

35 Countries included in the developed subsample are denoted by a * in Appendix Table A1.

${ }^{36}$ We also reestimated the $\beta$ 's for the two groups of countries. The differences across groups were not appreciable.
} 
rise in aggregate volatility of 0.0004 in the average developed country, and of 0.0022 , or five times as much, in the average developing country. In developed countries, the effect is also weaker when measured as a share of the average aggregate volatility. The increase in volatility corresponds to $14.6 \%$ of the average aggregate volatility found in the developed subsample, compared to $19.2 \%$ in the developing subsample. The relative importance of the three individual effects does not differ greatly between the two samples, as evident from Table 10. Perhaps surprisingly, the sector-level volatility and comovement effects are relatively less important in the developing country sample. The specialization effect, while still the largest quantitatively, is less important in the developed country sample.

The developed and developing countries differ significantly along every variable that goes into calculating the magnitudes. However, one might also like to know how changes in an individual variable affect these magnitudes. To do this, we go back to the full sample baseline calculation of the previous subsection, and vary $\sigma^{2}, \rho$, and $h$ individually. Table 11 reports the results. In this table, rather than evaluating the three effects using the sample means of $\sigma^{2}, \rho$, and $h$ as we had done above, we evaluate them using each of these at the $25^{\text {th }}$ and the $75^{\text {th }}$ percentile of its distribution, one by one. Thus, this table demonstrates how the sizes of the Sector Volatility Effect, the Comovement Effect, and the Specialization Effect differ between countries at the $25^{\text {th }}$ and the $75^{\text {th }}$ percentile in the distribution of $\sigma^{2}$, for example.

It turns out that moving from the $25^{\text {th }}$ to the $75^{\text {th }}$ percentile in the distribution of sector-level volatility increases the overall effect of trade opening by a factor of almost 5 . What is interesting here is that the strongest effect of changing $\sigma^{2}$ is not on the Sector Volatility Effect itself, but on the Specialization Effect: while the magnitude of the former almost triples, the latter increases by a factor of 4.4. The increase in $\sigma^{2}$ also doubles the magnitude of the comovement effect. By contrast, moving from the $25^{\text {th }}$ to the $75^{\text {th }}$ percentile in the distribution of $\rho$ hardly changes anything. The net effect is positive, but the increase in overall volatility due to trade is only $5 \%$ higher for the more correlated country. Differences in $h$ change the impact of trade appreciably, but much less than differences in $\sigma^{2}$ : moving from the $25^{\text {th }}$ to the $75^{\text {th }}$ percentile in the distribution of $h$ increases the overall impact of trade by a factor of 1.8 .

To summarize, the implied association between trade opening and aggregate volatility varies a great deal depending on country characteristics. For instance, the impact of the same trade opening is likely to be five times higher in absolute terms for a typical developing country compared to a typical developed country. Furthermore, the country characteristic that is by far most responsible for the differences in estimated impact of trade is sector-level volatility. The impact of trade on aggregate volatility is highest for countries whose sectors are already most volatile on average. Its magnitude is such that it cannot be ignored when considering the effects of trade opening in developing countries. Note that this estimated role of trade is obtained controlling for a wide variety of country characteristics, such as institutions, macroeconomic policies, or the overall level of development. 


\section{Changes in the Impact on Aggregate Volatility Across Decades}

The final exercise estimates how the association between trade and aggregate volatility changes over time. For this calculation, we reestimate the three baseline specifications in the previous section by decade, in order to obtain potentially different coefficients for $\widehat{\beta}_{\sigma}, \widehat{\beta}_{\rho}$, and $\widehat{\beta}_{h}$ to use in the magnitude calculations. We also evaluate $\sigma^{2}, \rho, h$, and $\sigma_{A-}$ at their means within each individual decade. The results of estimating the $\beta$ 's by decade are presented in Table 9, while the summary statistics by decade are given in Table T1. ${ }^{37}$ Examining the coefficients, it appears that the importance of trade for all three determinants of volatility rises over time. Between the 1970s and the 1990s, the coefficient in the sector-level volatility regressions increases by $30 \%$, the comovement coefficient by $45 \%$, while the specialization coefficient more than doubles. When it comes to summary statistics, there is a clear decrease in aggregate volatility in the sample. This is accompanied by a decrease in $\rho$, while $\sigma^{2}$ and $h$ fell slightly in the 1980s and increased in the 1990s.

The results are summarized in Table 10. Not surprisingly, the rising $\beta$ 's in the regressions over time imply that the estimated role of trade openness increases substantially. In the 1970s and $1980 \mathrm{~s}$, increasing trade openness from the $25^{\text {th }}$ to the $75^{\text {th }}$ percentile comes with a rise in aggregate volatility of 0.001 . In the $1990 \mathrm{~s}$, the same increase in trade openness is associated with an increase in aggregate volatility of 0.002 , double the absolute impact. As a share of aggregate volatility, the effect goes from less than $10 \%$ of the average in the 1970 s to $31 \%$ in the 1990s.

Also worth noting is how the relative importance of the three effects changes over time. In the cross-sectional exercise using 30-year averages, we found that the Specialization and the Sector Volatility Effects are the two most important ones, while the Comovement Effect is small in magnitude. It turns out that this pattern varies somewhat across decades, even as all three effects become larger in magnitude over time. In the 1970s, the Sector Volatility Effect is substantially greater than the other two, while the Specialization Effect is much weaker than in the full sample. Furthermore, relative to the full sample, the Comovement Effect is more important in the 1970s as well. Intriguingly, in the 1980s all three effects are more or less equal in absolute value, and only in the 1990s do we see the Comovement Effect falling substantially behind the other two.

The result that the impact of trade has become stronger over time is distinct from the simple observation that trade has increased over the period. The increase in trade itself need not imply that the relationship between trade and volatility would have strengthened. Perhaps more interestingly, this finding is not at all inconsistent with the fall in overall macroeconomic volatility over this period. What seems to be happening is that while aggregate volatility has decreased, differences between the volatilities of country-sectors are better explained by the variation in trade openness. These quantitative results are valuable in their own right as they

\footnotetext{
${ }^{37}$ The results in this section are valid as long as the coverage of sectors and countries does not vary dramatically
} across decades, which is the case in our data. 
reveal the changing nature of trade's impact on the macroeconomy over time. Furthermore, they provide a rich set of facts to build upon in future empirical and theoretical work aiming to better understand the nature of the global business cycle. For example, in the macroeconomics literature sector-level dynamics underlying aggregate business cycles have been explored in a closed economy, ${ }^{38}$ and recent work has moved to the firm level. ${ }^{39}$ Our results can help provide a foundation for future work in the open economy setting.

\section{Conclusion}

Whether increased trade openness has contributed to rising uncertainty and exposed countries to external shocks remains a much debated topic. This paper uses industry-level data to document several aspects of the relationship between openness and volatility. The main conclusions can be summarized as follows. First, higher trade in a sector is associated with higher volatility in that sector. Second, more trade also implies that the sector is less correlated with the rest of the economy. Third, higher overall trade openness comes with increased specialization in the economy. The sum of these effects implies that moving from the $25^{\text {th }}$ to the $75^{\text {th }}$ percentile in the distribution of trade openness is associated with an increase in aggregate volatility of about $17.3 \%$ of the average aggregate variance observed in our sample. The estimated impact differs a great deal between countries and over time, however. The same change in trade openness is accompanied by an estimated rise in aggregate volatility that is roughly five times higher in a typical developing country than in a typical developed country. Over time, the association between trade and volatility acting through all three channels has become stronger.

While the results in this paper are informative, our understanding of the trade-volatility relationship can be improved along many dimensions. For instance, the exercise in this paper imposes symmetry between sectors, and thus does not allow us to investigate whether some countries tend to specialize systematically in more or less risky sectors, something that could be another channel for the relationship between trade and volatility. We address this question in di Giovanni and Levchenko (2007), which can thus serve to complement the analysis carried out here. The change over time in the impact of trade on volatility also deserves much more careful study. In particular, the increasing impact of trade, together with growing trade itself, needs to be analyzed jointly with the well-documented fact that business cycle volatility has actually decreased over the same period. Finally, this paper remains silent on the relationship between trade and growth. This relationship must also be considered if we wish to make any claims on the welfare consequences of opening to trade. We consider these to be promising avenues for future research.

\footnotetext{
${ }^{38}$ For an early contribution, see Long and Plosser (1983).

${ }^{39}$ For example, see Comín and Philippon (2006) and Gabaix (2005).
} 


\section{SECTOR-LEVEL GRAVITy-BASEd INSTRUMENT}

This appendix gives a detailed description of the sector-level instrument for trade openness used in estimation. The material here draws heavily on the treatment in Do and Levchenko (2007), which can be used for more detailed reference. The strategy applies the methodology of Frankel and Romer (1999) at sector level. For each industry $i$, we run the Frankel and Romer regression:

$$
\begin{aligned}
\log _{i c d}= & \alpha+\eta_{i}^{1} \text { ldist }_{c d}+\eta_{i}^{2} \text { lpop }_{c}+\eta_{i}^{3} \text { larea }_{c}+\eta_{i}^{4} \text { lpop }_{d}+\eta_{i}^{5} \text { larea }_{d}+\eta_{i}^{6} \text { landlocked }_{c d}+ \\
& \eta_{i}^{7} \text { border }_{c d}+\eta_{i}^{8} \text { border }_{c d} * \text { ldist }_{c d}+\eta_{i}^{9} \text { border }_{c d} * \text { pop }_{c}+\eta_{i}^{10} \text { border }_{c d} * \text { area }_{c}+ \\
& \eta_{i}^{11} \text { border }_{c d} * \operatorname{pop}_{d}+\eta_{i}^{12} \text { border }_{c d} * \text { area }_{d}+\eta_{i}^{13} \text { border }_{c d} * \text { landlocked }_{c d}+\varepsilon_{i c d}
\end{aligned}
$$

where $\log T_{i c d}$ is the $\log$ of bilateral trade as a share of sectoral output in industry $i$, from country $c$ to country $d$. The right-hand side consists of the geographical variables. In particular, ldist $_{c d}$ is the log of the distance between the two countries, defined as distance between the major cities in the two countries, $l p o p_{c}$ is the $\log$ of the population of country $c$, lare $_{c}$ is the log of land area, landlocked $d_{c d}$ takes the value of zero, one, or two depending on whether none, one, or both of the trading countries are landlocked, and border $c$ is the dummy variable for a common border. The right-hand side of the specification is identical to the one Frankel and Romer (1999) use.

Having estimated equation (A.1) for each industry, we then obtain the predicted logarithm of industry $i$ bilateral trade to output from country $c$ to each of its trading partners indexed by $d$, $\widehat{\log T}_{i c d}$. In order to construct the predicted overall industry $i$ trade as a share of output from country $c$, we take the exponential of the predicted bilateral log of trade, and sum over the trading partner countries $d=1, \ldots, C$, exactly as in Frankel and Romer (1999):

$$
\widehat{T}_{i c}=\sum_{\substack{d=1 \\ d \neq c}}^{C} e^{\widehat{\operatorname{LogT}}_{i c d}} .
$$

That is, predicted total trade as a share of sectoral output for each industry and country is the sum of the predicted bilateral trade to output over all trading partners.

We require an instrument for trade openness at sector level. How can the strategy described above yield this type of instrument even though the variation in the gravity variables in equation (A.1) is by country? The key is that we estimate an individual gravity equation for each sector. Thus, crucially for the identification strategy, if the vector of estimated gravity coefficients $\eta_{i}$ differs across sectors, so will the predicted total exports $\widehat{T}_{i c}$ across sectors $i$ within the same country.

The intuition is easiest to explain in terms of the coefficient on distance. Suppose that some industries are more sensitive to distance than others. Then, countries that are more remote - 
farther from the potential trading partners - will have relatively higher predicted trade in sectors that are less distance-sensitive. Going beyond the distance coefficient, the empirical strategy relies on variation in all of the regression coefficients in equation (A.1), along with the entire battery of exporting and destination country characteristics.

It is therefore crucial for this procedure that the gravity coefficients (hopefully all 13 of them) vary appreciably across sectors. When we discuss the actual estimation results for the gravity regressions, we demonstrate that this is indeed the case. But before describing the gravity results, it is worth mentioning briefly the theoretical rationales and existing empirical evidence on the variation in sector-level gravity coefficients.

Existing research has focused on the effect of trade barriers on trade volumes. Thus, it is most informative about the variation in the coefficients on distance and common border variables, that are often used as proxies for bilateral trade barriers. Anderson and van Wincoop $(2003,2004)$ show that the estimated coefficients on distance and common border in the gravity model are a function of (i) trade costs and (ii) the elasticity of substitution between product varieties within the sector. Available direct estimates of freight costs do indeed show large variation across sectors. According to Hummels (2001), freight costs in the U.S. in 1994 ranged between $1 \%$ and $27 \%$ across sectors. In addition to the direct shipping costs, goods may differ in the cost of acquiring information about them. Rauch (1999) and Rauch and Trindade (2002) find that the volume of trade reacts differently to informational barriers in differentiated goods sectors compared to homogeneous ones. Thus, empirically it does seem to be the case that trade costs - both simple and informational - vary significantly across industries. When it comes to the estimated elasticity of substitution across sectors, a large number of studies utilizing various approaches reach quantitatively similar conclusions. Anderson and van Wincoop (2004) summarize existing evidence, which produces a range of estimated elasticities from 3 to 10across industries. In addition to trade costs and elasticities of substitution, Chaney (2006) demonstrates that the degree of firm heterogeneity, which varies across sectors, also has a significant effect on the sector-specific distance coefficient in the gravity regression.

To summarize, there are strong reasons to expect the coefficients in equation (A.1) to vary across sectors. But is this the case in practice? Estimating the gravity model using sector-level data is becoming increasingly common (Rauch 1999, Rauch and Trindade 2002, Hummels 2001, Evans 2003, Feenstra, Markusen and Rose 2001, Lai and Trefler 2001, Chaney 2006). Though studies differ in the level of sectoral disaggregation and specifications, it is indeed typical to find significant variation in the gravity coefficients across sectors. For instance, Hummels (2001) finds that the distance coefficients vary from 0 to -1.07 in his sample of sectors, while the coefficients on the common border variable range from positive and significant (as high as 1.22) to negative and significant (as low as -1.23). Chaney (2006) reports that it is common to find sector-specific distance coefficients ranging from -0.5 to -1.5 . When we present the results of our own estimation, we will compare them to these studies. 
We now discuss another potentially important issue, namely, the treatment of zero trade observations. In our sample, only about two-thirds of the possible exporter-importer pairs record positive exports, in any sector. At the level of individual industry, on average only a third of possible country-pairs have strictly positive exports, in spite of the coarse level of aggregation (28 sectors). ${ }^{40}$ How does our estimation procedure deal with zero observations? As a preliminary point, because we develop an instrument for trade patterns rather than trade volumes, we can safely disregard country pairs in which no trade is observed in any sector. Following the large majority of gravity studies, we take logs of trade values, and thus our baseline gravity estimation procedure ignores zeros. Hence, we generate predicted values of trade only when the actual value is positive. One interpretation of our procedure is that it "predicts" zero trade when it observes zero trade. This strategy may contaminate the instrument if the estimated gravity coefficients would instead predict large trade values for some countries and sectors in which actual trade is zero.

We deal with this potential problem by instead estimating the gravity regression in levels using the Poisson pseudo-maximum likelihood estimator suggested by Santos Silva and Tenreyro (2006). The advantage of this procedure is that it actually includes zero observations in the estimation, and can predict both zero and nonzero trade values in-sample from the same estimated equation. Its disadvantage is that it assumes a particular likelihood function, and is not (yet) a standard way of estimating gravity equations found in the literature. ${ }^{41}$

In order to build the instrument, our procedure estimates equation (A.1) for each industry. In order to do so, we retain information on bilateral trade flows from the World Trade Database, deflating them by output from UNIDO. We merge bilateral trade data with geography variables taken from Centre d'Etudes Prospectives et d'Informations Internationales (CEPII). The CEPII database contains information on bilateral distance between the major cities for each pair of countries, whether two countries share a border, as well as information on land area and whether a country is landlocked. ${ }^{42}$ Population data are taken from World Bank's World Development Indicators for the period 1970 to 1999. The left-hand side variable is averaged over the period 1970 to 1999 , allowing us to increase the sample size as trade observations are sometimes missing in individual years. In the set of the sector-level regressions, the smallest number of observations is 4200 , and the largest is 8257 , with a mean

\footnotetext{
40 These two calculations make the common assumption that missing trade observations represent zeros (Helpman, Melitz and Rubinstein 2006).

41 Alternatively, instead of predicting in-sample, we used the baseline log-linear gravity model to predict out-of-sample. Thus, for those observations that are zero or missing and not used in the actual estimation, we still predict trade. (More precisely, for a given exporter-importer pair, we predict bilateral trade out-of-sample for all 28 sectors as long as there are any bilateral trade for that country pair in at least one of the 28 sectors.) This completely eliminates the problem of predicting zeros "too well" in the baseline instrument, but may introduce an appreciable amount of noise if there are too many zeros that are ignored in the gravity estimation. The results are robust to using this alternative strategy.

42 The data set is available online at http://www. cepii.fr/anglaisgraph/bdd/distances.htm.
} 
of 6270 . The $R^{2}$ 's range from 0.20 to 0.43 , with a mean of 0.36 .

Because the right-hand side variables are the same in all regressions, the empirical strategy in this paper would only work if the gravity coefficients differ significantly across sectors. Thus, the first important question is whether or not there is much variation in the estimated coefficients. Figure A1 presents, for each coefficient, the range of estimates across sectors. Below the plot for each coefficient, we report the minimum, median, and maximum values that the estimates take across all industries. It is apparent that the coefficient estimates differ a great deal between sectors. For instance, the distance coefficient pictured in the first plot ranges from -0.83 to -1.6 . This is very close to what is reported in Chaney (2006). Note that several of the coefficients, such as the one on the common border dummy, actually range from positive to negative, a finding similar to Hummels (2001). The variation in the Poisson coefficients, which we do not picture here to conserve space, exhibit a similar degree of variation.

We formally tested for equality of the gravity coefficients by pooling observations across sectors but letting the each coefficient vary by sector. The data overwhelmingly reject the null hypothesis that all of the coefficients are the same across sectors. Furthermore, we tested the hypothesis of equality of each individual coefficient across sectors. Out of 13 coefficients, the null that they are the same across sectors is rejected in 9 cases. 


\section{The Symmetry Assumption}

This appendix gives the detailed derivations showing that the assumption of symmetry across sectors of the $\sigma_{i}^{2}$ and $\rho_{i, A-i}$ in equation (8) does not appreciably affect the calculation in equation (10). More precisely, it demonstrates that imposing symmetry across sectors, while ignoring a great deal of information about the structure of production in individual countries, produces reliable estimates for the average effect of trade openness on aggregate volatility across countries.

The derivation proceeds in two steps. The first step starts with the fully general identity for the aggregate variance, and rewrites it as a sum of the symmetric term in equation (8), and some additional terms. The second step shows that these additional terms are small on average as a fraction of the level of variance in our sample of countries, and do not significantly affect the computation of the Sector Volatility and Comovement Effects.

For each country, the identity for the aggregate variance, $\sigma_{A}^{2}$, can be written as a function of $\sigma_{i}^{2}$ and $\rho_{i, A-i}$ as (also equation 7):

$$
\begin{aligned}
\sigma_{A}^{2}= & h \sigma^{2}+(1-h) \bar{\sigma}_{i, A-i}+\sum_{i=1}^{\mathcal{I}} a_{i}^{2}\left(\sigma_{i}^{2}-\sigma^{2}\right) \\
& +\sum_{i=1}^{\mathcal{I}} a_{i}\left(1-a_{i}\right)\left(\rho_{i, A-i} \sigma_{i} \sigma_{A-i}-\bar{\sigma}_{i, A-i}\right),
\end{aligned}
$$

where, following the notation in the main text, $\sigma^{2}$ is the average variance across sectors, while $\bar{\sigma}_{i, A-i} \equiv \frac{1}{\mathcal{I}} \sum_{i=1}^{\mathcal{I}} \sigma_{i, A-i}$ is the average covariance of a sector with the rest of the economy.

To begin considering how equation (B.3) differs from (8), note that (B.3) uses the average covariance of a sector with the rest of the manufacturing sector, $\bar{\sigma}_{i, A-i}$, rather than the product of the average correlation with the average standard deviations across sectors, $\rho \sigma \sigma_{A-}$. Straightforward manipulation allows one to rewrite the average as:

$\bar{\sigma}_{i, A-i}=\rho \sigma \sigma_{A-}+\frac{\mathcal{I}-2}{\mathcal{I}} \operatorname{Cov}_{i}\left(\rho_{i, A-i}, \sigma_{i}\right) \sigma_{A-}+\frac{1}{\mathcal{I}} \sum_{i=1}^{\mathcal{I}} \rho_{i, A-i} \sigma_{i}\left(\sigma_{i, A-i}-\sigma_{A-}\right)$. It turns out that in our sample of countries, the median value of the first term, $\rho \sigma \sigma_{A-}$, is about 0.0028 , compared to the median value of the second term of -0.00012 , more than 20 times smaller. The third term is even less important, with a median of -0.00002 , less than one hundredth of the value used in the paper. This is not surprising. Since an average sector is very small compared to the aggregate in this sample of countries, $\sigma_{i, A-i} \approx \sigma_{A-}$ for most sectors in most countries.

We conclude that it is a good approximation to write $\bar{\sigma}_{i, A-i} \approx \rho \sigma \sigma_{A-}$, and the identity for aggregate variance becomes:

$$
\begin{aligned}
\sigma_{A}^{2} & \approx h \sigma^{2}+(1-h) \rho \sigma \sigma_{A-} \\
& +\sum_{i=1}^{\mathcal{I}} a_{i}^{2}\left(\sigma_{i}^{2}-\sigma^{2}\right)+\sum_{i=1}^{\mathcal{I}} a_{i}\left(1-a_{i}\right)\left(\rho_{i, A-i} \sigma_{i} \sigma_{A-i}-\rho \sigma \sigma_{A-}\right) .
\end{aligned}
$$


The first two terms are identical to the approximate formula for the variance used in the paper to set up our decomposition, equation (8). The third term reflects whether a country on average specializes in risky or safe sectors. It equals zero if all sectors have the same variance $\left(\sigma_{i}^{2}=\sigma^{2} \forall i\right)$, or if the economy is perfectly diversified $\left(a_{i}=\frac{1}{\mathcal{I}} \forall i\right)$. It will be positive in a country with higher production shares in sectors that are riskier than average, and vice versa. Similarly, the last term reflects whether a country has higher production shares in sectors that are on average more correlated with the aggregate economy.

As a preliminary point, we can ascertain how important these terms are in the data. The median value across countries of the symmetric component of the variance, $h \sigma^{2}+(1-h) \rho \sigma \sigma_{A-}$ in our sample of countries is about 0.006 . The median of $\sum_{i=1}^{\mathcal{I}} a_{i}^{2}\left(\sigma_{i}^{2}-\sigma^{2}\right)$ is -0.0007 , almost 10 times lower. The median of $\sum_{i=1}^{\mathcal{I}} a_{i}\left(1-a_{i}\right)\left(\rho_{i, A-i} \sigma_{i} \sigma_{A-i}-\rho \sigma \sigma_{A-}\right)$ is -0.00004 , more than 100 times lower than the median value of what we take to be our approximation for the aggregate variance. Thus, it appears that while there could be variation in how important these terms are for shaping aggregate variances of individual countries, their importance is minor on average across countries.

How do the third and fourth terms affect the calculations of the impact of trade in equation (10)? We now use equation (B.4) to evaluate whether the third and fourth terms affect appreciably the calculations for the Sector Volatility and Comovement Effects. Write the Sector Volatility Effect as a Taylor approximation of the change in $\sigma_{A}^{2}$ as a function of a change in $\sigma_{i}^{2}$ for all $i$ :

$$
\Delta \sigma_{A}^{2} \approx \sum_{i=1}^{\mathcal{I}} \frac{\partial \sigma_{A}^{2}}{\partial \sigma_{i}^{2}} \Delta \sigma_{i}^{2} .
$$

Note that this formula is completely general, and does not rely on any symmetry assumptions at this stage. Using equation (B.4) and the fact that $\sigma^{2} \equiv \frac{1}{\mathcal{I}} \sum_{i=1}^{\mathcal{I}} \sigma_{i}^{2}$, for each $i$ this derivative equals:

$$
\begin{aligned}
\frac{\partial \sigma_{A}^{2}}{\partial \sigma_{i}^{2}} & =h \frac{1}{\mathcal{I}}+(1-h) \rho \frac{\sigma_{A-}}{2 \sigma} \frac{1}{\mathcal{I}} \\
& +\left(a_{i}^{2}-\frac{1}{\mathcal{I}} \sum_{i=1}^{\mathcal{I}} a_{i}^{2}\right) \\
& +\frac{\sigma_{A-}}{2 \sigma}\left[a_{i}\left(1-a_{i}\right) \rho_{i, A-i}-\frac{1}{\mathcal{I}} \sum_{i=1}^{\mathcal{I}} a_{i}\left(1-a_{i}\right) \rho\right] .
\end{aligned}
$$

The key symmetry assumption is that $\Delta \log ($ Openness) is the same across sectors. That is, the thought experiment in the paper is that of an identical increase in trade openness across all sectors. This assumption follows most naturally from the regression-based approach of this paper, which estimates the average effect of the level of trade openness across countries and sectors. Since the sector volatility regressions are estimated in logs, this leads to the same 
proportional increase in $\sigma_{i}^{2}$ across sectors, and therefore the actual $\Delta \sigma_{i}^{2}$ will vary across sectors: $\Delta \sigma_{i}^{2}=\sigma_{i}^{2} \widehat{\beta}_{\sigma} \Delta \log ($ Openness $)=\frac{\sigma_{i}^{2}}{\sigma^{2}} \Delta \sigma^{2}$, where $\Delta \sigma^{2} \equiv \widehat{\beta}_{\sigma} \Delta \log ($ Openness $)$ is the average change in variance as defined by equation (11). Combining equations (B.5) and (B.6) with this assumption leads to the following expression:

$$
\begin{aligned}
\Delta \sigma_{A}^{2} \approx\left(h+(1-h) \rho \frac{\sigma_{A-}}{2 \sigma}\right) \Delta \sigma^{2}+ \\
{\left[\sum_{i=1}^{\mathcal{I}}\left(a_{i}^{2}-\frac{1}{\mathcal{I}} \sum_{j=1}^{\mathcal{I}} a_{j}^{2}\right) \frac{\sigma_{i}^{2}}{\sigma^{2}}\right] \Delta \sigma^{2}+} \\
{\left[\sum_{i=1}^{\mathcal{I}}\left(a_{i}\left(1-a_{i}\right) \rho_{i, A-i}-\rho \frac{1}{\mathcal{I}} \sum_{j=1}^{\mathcal{I}} a_{j}\left(1-a_{j}\right)\right) \frac{\sigma_{A-}}{2 \sigma_{i}} \frac{\sigma_{i}^{2}}{\sigma^{2}}\right] \Delta \sigma^{2} . }
\end{aligned}
$$

The first term is the Sector Volatility Effect analyzed in the paper. The second term follows from the fact that proportional changes in volatility will increase the aggregate variance by more in countries that have systematically higher production shares in sectors more volatile than the average. This term will be zero in countries that are perfectly diversified $\left(a_{i}=\frac{1}{\mathcal{I}} \forall i\right)$, or if all sectors have the same variance $\left(\sigma_{i}^{2}=\sigma^{2} \forall i\right)$. The last term has a similar interpretation with respect to the correlation with the aggregate economy. When these terms are not zero, they will contribute to the Sector Volatility Effect. They turn out, however, not to be important quantitatively. In our sample of countries, the value of $\left(h+(1-h) \rho \frac{\sigma_{A-}}{2 \sigma}\right)$ - which goes into calculating the Sector Volatility Effect in the paper - is $0.188,{ }^{43}$ compared to the median value across countries of the second term in brackets of -0.019 , an order of magnitude lower. The impact of the third term is even lower, with a median of 0.0006 , which is negligible.

Similarly, it is possible to write out the general expression for the Comovement Effect that does not rely on any symmetry assumptions:

$$
\Delta \sigma_{A}^{2} \approx \sum_{i=1}^{\mathcal{I}} \frac{\partial \sigma_{A}^{2}}{\partial \rho_{i, A-i}} \Delta \rho_{i, A-i}
$$

Proceeding in similar steps, we use equation (B.4) to compute each derivative $\frac{\partial \sigma_{A}^{2}}{\partial \rho_{i, A-i}}$. Since the correlation regressions are estimated in levels, imposing the same $\Delta \log ($ Openness $)$ across sectors implies that the absolute change in the correlation is also the same across sectors: $\Delta \rho_{i, A-i}=\Delta \rho$. This means that the general form for $\Delta \sigma_{A}^{2}$ can be written as:

$$
\Delta \sigma_{A}^{2} \approx\left[(1-h) \sigma \sigma_{A-}+\sigma_{A-} \sum_{i=1}^{\mathcal{I}} a_{i}\left(1-a_{i}\right)\left(\sigma_{i}-\sigma\right)\right] \Delta \rho
$$

Once again, the first term in brackets is the Comovement Effect analyzed in the paper. The second comes from the asymmetry of sectors with respect to $\sigma_{i}$. This term exists because

\footnotetext{
${ }^{43}$ As described in the main text, this value is obtained using the average values of $h, \rho$, and $\sigma$ found in this sample of countries. Alternatively, we can also calculate the term $\left(h+(1-h) \rho \frac{\sigma_{A-}}{2 \sigma}\right)$ for each country, and take the median of that, which turns out to be 0.184 . This further confirms the robustness of our approach.
} 
changes in the correlation coefficient will affect the covariances conditional on the standard deviation of the sector. The relative importance of the second term turns out to be quite minor as well. The value of $(1-h) \sigma \sigma_{A-}$, which is used to calculate the Comovement Effect in the paper is 0.0112 . By contrast, across countries the median for the second term is -0.0007 , more than 10 times lower.

We conclude from these exercises that as long as $\Delta \log ($ Openness $)$ is the same across sectors - as follows naturally from the regression-based approach — imposing symmetry on the levels of $\sigma^{2}$ and $\rho$ across sectors does not appreciably affect the calculations of the Sector Volatility and Comovement Effects. Finally, it is evident from equation (B.3) that we cannot perform a similar exercise for the Specialization Effect. This is because we cannot take the derivative of the third and fourth terms in equation (B.3) with respect to $h$. As discussed above, these terms could be large and positive in countries that specialize systematically in sectors with higher volatility and higher correlation with the aggregate economy. Analyzing the effect of these terms requires focusing on the variation in patterns of export specialization. A companion paper (di Giovanni and Levchenko 2007) is entirely devoted to that topic. However, these terms are also very small in magnitude on average. Because this paper estimates the average effects of the three channels on aggregate volatility, the full treatment of the country-specific information contained in these extra terms is beyond the scope of the analysis presented here. 
Table 1. Volatility of Annual Output Growth per Worker: Cross-Sectional Results

\begin{tabular}{lcccccc}
\hline \hline & $(1)$ & $(2)$ & $(3)$ & $(4)$ & $(5)$ & $(6)$ \\
\hline Trade/Output & $0.231^{* *}$ & $0.231^{* *}$ & $0.197 * *$ & $0.150^{* *}$ & $0.227 *$ & $0.211+$ \\
& $(0.023)$ & $(0.029)$ & $(0.018)$ & $(0.028)$ & $(0.091)$ & $(0.123)$ \\
Output per worker & 0.007 & $-0.500^{* *}$ & $0.347 * *$ & 0.004 & 0.026 & 0.022 \\
& $(0.038)$ & $(0.052)$ & $(0.033)$ & $(0.048)$ & $(0.054)$ & $(0.057)$ \\
\hline Observations & 1573 & 1573 & 1573 & 1573 & 1573 & 1573 \\
$R^{2}$ & 0.058 & 0.240 & 0.618 & 0.715 & - & - \\
\hline$\mu_{c}$ & no & no & yes & yes & yes & yes \\
$\mu_{i}$ & no & yes & no & yes & yes & yes \\
Estimation & OLS & OLS & OLS & OLS & IV-log-linear & IV-PMLE \\
\hline
\end{tabular}

Notes: Robust standard errors in parentheses. + significant at 10\%; $*$ significant at 5\%; ** significant at $1 \%$. The sample period is 1970-99. The dependent variable is the log variance of the growth rate of output per worker, 1970-99. All regressors are in natural logs, trade/output is the period average, and output per worker is the period's initial value. $\mu_{c}$ denotes the country fixed effects. $\mu_{i}$ denotes the sector fixed effects. IV-log-linear uses as instrument the predicted trade shares based on the log-linear gravity model. IV-PMLE uses as instrument predicted trade shares based on the gravity model applied to positive and zero trade flows using the Poisson Pseudo-Maximum Likelihood estimator.

Table 2. Volatility of Annual Output Growth per Worker: Panel Results

\begin{tabular}{lcccccccc}
\hline \hline & $(1)$ & $(2)$ & $(3)$ & $(4)$ & $(5)$ & $(6)$ & $(7)$ & $(8)$ \\
\hline Trade/Output & $0.215^{* *}$ & $0.215^{* *}$ & $0.207^{* *}$ & $0.203^{* *}$ & $0.179^{* *}$ & $0.209^{* *}$ & $0.240^{* *}$ & $0.146^{*}$ \\
& $(0.020)$ & $(0.023)$ & $(0.015)$ & $(0.021)$ & $(0.022)$ & $(0.022)$ & $(0.049)$ & $(0.062)$ \\
Output per worker & -0.055 & $-0.610^{* *}$ & $0.304^{* *}$ & 0.027 & 0.073 & 0.037 & $-0.144+$ & -0.053 \\
& $(0.036)$ & $(0.046)$ & $(0.030)$ & $(0.043)$ & $(0.045)$ & $(0.044)$ & $(0.086)$ & $(0.104)$ \\
\hline Observations & 4378 & 4378 & 4378 & 4378 & 4378 & 4378 & 4378 & 4378 \\
$R^{2}$ & 0.050 & 0.181 & 0.430 & 0.489 & 0.582 & 0.499 & 0.678 & 0.775 \\
\hline$\mu_{t}$ & yes & yes & yes & yes & no & no & yes & no \\
$\mu_{c}$ & no & no & yes & yes & yes & no & no & no \\
$\mu_{i}$ & no & yes & no & yes & no & yes & no & no \\
$\mu_{c} \times \mu_{i}$ & no & no & no & no & no & no & yes & yes \\
$\mu_{c} \times \mu_{t}$ & no & no & no & no & no & yes & no & yes \\
$\mu_{i} \times \mu_{t}$ & no & no & no & no & yes & no & no & yes \\
\hline
\end{tabular}

Notes: Standard errors clustered at country $\times$ sector level in parentheses. + significant at $10 \%$; $*$ significant at $5 \%$; ** significant at $1 \%$. The sample period is $1970-99$. The dependent variable is the log variance of the growth rate of output per worker over ten-year periods: 1970-79, 1980-89, 1990-99. All regressors are in natural logs, trade/output is averaged over the ten-year periods, and output per worker is the ten-year period's initial value. $\mu_{c}$ denotes the country fixed effects. $\mu_{i}$ denotes the sector fixed effects. $\mu_{t}$ denotes the time fixed effects. All specifications are estimated using OLS. 
Table 3. Volatility of Annual Growth of Quantity per Worker and of Prices: Cross-Sectional Results

\begin{tabular}{|c|c|c|c|c|c|c|}
\hline \multicolumn{7}{|c|}{ I. Quantity per Worker } \\
\hline & (1) & (2) & (3) & (4) & (5) & (6) \\
\hline \multirow[t]{2}{*}{ Trade/Output } & $0.262 * *$ & $0.256 * *$ & $0.264 * *$ & $0.215^{* *}$ & $0.345^{* *}$ & $0.388^{*}$ \\
\hline & $(0.025)$ & $(0.032)$ & $(0.020)$ & $(0.034)$ & $(0.108)$ & $(0.167)$ \\
\hline \multirow{2}{*}{ Output per worker } & $-0.254 * *$ & $-0.550 * *$ & 0.002 & -0.051 & -0.015 & -0.003 \\
\hline & $(0.042)$ & $(0.059)$ & $(0.032)$ & $(0.050)$ & $(0.058)$ & $(0.065)$ \\
\hline Observations & 1379 & 1379 & 1379 & 1379 & 1379 & 1379 \\
\hline$R^{2}$ & 0.113 & 0.205 & 0.615 & 0.690 & - & - \\
\hline$\mu_{c}$ & no & no & yes & yes & yes & yes \\
\hline$\mu_{i}$ & no & yes & no & yes & yes & yes \\
\hline \multirow[t]{3}{*}{ Estimation } & OLS & OLS & OLS & OLS & IV-log-linear & IV-PMLE \\
\hline & & & Price & & & \\
\hline & (1) & (2) & (3) & (4) & (5) & (6) \\
\hline \multirow[t]{2}{*}{ Trade/Output } & $0.188 * *$ & $0.190 * *$ & $0.191 * *$ & $0.189 * *$ & $0.340 * *$ & $0.446^{*}$ \\
\hline & $(0.022)$ & $(0.029)$ & $(0.019)$ & $(0.034)$ & $(0.123)$ & $(0.184)$ \\
\hline \multirow[t]{2}{*}{ Output per worker } & $-0.103 *$ & $-0.358 * *$ & $0.103 * *$ & 0.034 & 0.076 & 0.106 \\
\hline & $(0.041)$ & $(0.055)$ & $(0.037)$ & $(0.056)$ & $(0.067)$ & $(0.072)$ \\
\hline Observations & 1377 & 1377 & 1377 & 1377 & 1377 & 1377 \\
\hline$R^{2}$ & 0.066 & 0.172 & 0.504 & 0.584 & - & - \\
\hline$\mu_{c}$ & no & no & yes & yes & yes & yes \\
\hline$\mu_{i}$ & no & yes & no & yes & yes & yes \\
\hline Estimation & OLS & OLS & OLS & OLS & IV-log-linear & IV-PMLE \\
\hline
\end{tabular}

Notes: Robust standard errors in parentheses. + significant at 10\%; * significant at 5\%; ** significant at $1 \%$. The sample period is 1970-99. The dependent variable is the log variance of the growth rate of quantity per worker or prices, 1970-99. All regressors are in natural logs, trade/output is the period average, and output per worker is the period's initial value. $\mu_{c}$ denotes the country fixed effects. $\mu_{i}$ denotes the sector fixed effects. IV-log-linear uses as instrument the predicted trade shares based on the log-linear gravity model. IV-PMLE uses as instrument predicted trade shares based on the gravity model applied to positive and zero trade flows using the Poisson Pseudo-Maximum Likelihood estimator. 
Table 4. Volatility of Annual Growth of Quantity per Worker and of Prices: Cross-Sectional Results

\begin{tabular}{|c|c|c|c|c|c|c|}
\hline \multicolumn{7}{|c|}{ I. Number of Firms } \\
\hline & (1) & (2) & (3) & (4) & $(5)$ & (6) \\
\hline \multirow[t]{2}{*}{ Trade/Output } & $0.240 * *$ & $0.269 * *$ & $0.196 * *$ & $0.171 * *$ & 0.188 & $0.324 *$ \\
\hline & $(0.031)$ & $(0.038)$ & $(0.028)$ & $(0.041)$ & $(0.125)$ & $(0.161)$ \\
\hline \multirow[t]{2}{*}{ Output per worker } & -0.065 & $-0.367 * *$ & $0.157 * *$ & 0.026 & 0.032 & 0.077 \\
\hline & $(0.047)$ & $(0.071)$ & $(0.046)$ & $(0.069)$ & $(0.080)$ & $(0.088)$ \\
\hline Observations & 1329 & 1329 & 1329 & 1329 & 1329 & 1329 \\
\hline$R^{2}$ & 0.045 & 0.122 & 0.517 & 0.571 & - & - \\
\hline$\mu_{c}$ & no & no & yes & yes & yes & yes \\
\hline$\mu_{i}$ & no & yes & no & yes & yes & yes \\
\hline Estimation & OLS & OLS & OLS & OLS & IV-log-linear & IV-PMLE \\
\hline \multicolumn{7}{|c|}{ II. Output-per-Firm } \\
\hline & (1) & (2) & (3) & (4) & (5) & (6) \\
\hline \multirow[t]{2}{*}{ Trade/Output } & $0.206 * *$ & $0.194 * *$ & $0.206 * *$ & $0.158 * *$ & 0.041 & 0.169 \\
\hline & $(0.026)$ & $(0.033)$ & $(0.023)$ & $(0.036)$ & $(0.108)$ & $(0.151)$ \\
\hline \multirow[t]{2}{*}{ Output per worker } & -0.027 & $-0.371 * *$ & $0.200 * *$ & -0.030 & -0.067 & -0.026 \\
\hline & $(0.039)$ & $(0.057)$ & $(0.041)$ & $(0.065)$ & $(0.074)$ & $(0.078)$ \\
\hline Observations & 1342 & 1342 & 1342 & 1342 & 1342 & 1342 \\
\hline$R^{2}$ & 0.046 & 0.158 & 0.499 & 0.576 & - & - \\
\hline$\mu_{c}$ & no & no & yes & yes & yes & yes \\
\hline$\mu_{i}$ & no & yes & no & yes & yes & yes \\
\hline Estimation & OLS & OLS & OLS & OLS & IV-log-linear & IV-PMLE \\
\hline
\end{tabular}

Notes: Robust standard errors in parentheses. + significant at 10\%; * significant at 5\%; ** significant at 1\%. The sample period is 1970-99. The dependent variable is the log variance of the number of firms or output per firm 1970-99. All regressors are in natural logs, trade/output is the period average, and output per worker is the period's initial value. $\mu_{c}$ denotes the country fixed effects. $\mu_{i}$ denotes the sector fixed effects. IV-log-linear uses as instrument the predicted trade shares based on the log-linear gravity model. IV-PMLE uses as instrument predicted trade shares based on the gravity model applied to positive and zero trade flows using the Poisson Pseudo-Maximum Likelihood estimator. 
Table 5. Correlation of Annual Output Growth per Worker with the Rest of the Manufacturing Sector: Cross-Section Results

\begin{tabular}{lcccccc}
\hline \hline & $(1)$ & $(2)$ & $(3)$ & $(4)$ & $(5)$ & $(6)$ \\
\hline Trade/Output & $-0.025^{* *}$ & $-0.061^{* *}$ & -0.004 & $-0.042^{* *}$ & -0.055 & $-0.093^{*}$ \\
& $(0.007)$ & $(0.009)$ & $(0.007)$ & $(0.011)$ & $(0.035)$ & $(0.045)$ \\
Output per worker & 0.012 & 0.014 & $-0.018+$ & $-0.050^{* *}$ & $-0.053^{* *}$ & $-0.065^{* *}$ \\
& $(0.010)$ & $(0.014)$ & $(0.011)$ & $(0.018)$ & $(0.020)$ & $(0.022)$ \\
\hline Observations & 1571 & 1571 & 1571 & 1571 & 1571 & 1571 \\
$R^{2}$ & 0.013 & 0.104 & 0.287 & 0.359 & - & - \\
\hline$\mu_{c}$ & no & no & yes & yes & yes & yes \\
$\mu_{i}$ & no & yes & no & yes & yes & yes \\
Estimation & OLS & OLS & OLS & OLS & IV-log-linear & IV-PMLE \\
\hline
\end{tabular}

Notes: Robust standard errors in parentheses. + significant at 10\%; * significant at 5\%; ** significant at $1 \%$. The sample period is 1970-99. The dependent variable is the correlation of the growth rate of output per worker with the rest of the manufacturing sector, 1970-99. All regressors are in natural logs, trade/output is the period average, and output per worker is the period's initial value. $\mu_{c}$ denotes the country fixed effects. $\mu_{i}$ denotes the sector fixed effects. IV-log-linear uses as instrument the predicted trade shares based on the log-linear gravity model. IV-PMLE uses as instrument predicted trade shares based on the gravity model applied to positive and zero trade flows using the Poisson Pseudo-Maximum Likelihood estimator. 
Table 6. Correlation of Annual Output Growth per Worker with the Rest of the Manufacturing Sector: Panel Results

\begin{tabular}{lcccccccc}
\hline \hline & $(1)$ & $(2)$ & $(3)$ & $(4)$ & $(5)$ & $(6)$ & $(7)$ & $(8)$ \\
\hline Trade/Output & $-0.025^{* *}$ & $-0.045^{* *}$ & $-0.020^{* *}$ & $-0.046^{* *}$ & $-0.037^{* *}$ & $-0.051^{* *}$ & $-0.042^{*}$ & -0.024 \\
& $(0.007)$ & $(0.009)$ & $(0.008)$ & $(0.010)$ & $(0.011)$ & $(0.010)$ & $(0.018)$ & $(0.023)$ \\
Output per worker & -0.012 & 0.008 & $-0.039 * *$ & $-0.044 *$ & $-0.057 * *$ & $-0.038+$ & -0.017 & -0.036 \\
& $(0.012)$ & $(0.016)$ & $(0.013)$ & $(0.019)$ & $(0.021)$ & $(0.020)$ & $(0.031)$ & $(0.036)$ \\
\hline Observations & 4299 & 4299 & 4299 & 4299 & 4299 & 4299 & 4299 & 4299 \\
$R^{2}$ & 0.006 & 0.039 & 0.166 & 0.195 & 0.267 & 0.206 & 0.667 & 0.743 \\
\hline$\mu_{t}$ & yes & yes & yes & yes & no & no & yes & no \\
$\mu_{c}$ & no & no & yes & yes & yes & no & no & no \\
$\mu_{i}$ & no & yes & no & yes & no & yes & no & no \\
$\mu_{c} \times \mu_{i}$ & no & no & no & no & no & no & yes & yes \\
$\mu_{c} \times \mu_{t}$ & no & no & no & no & no & yes & no & yes \\
$\mu_{i} \times \mu_{t}$ & no & no & no & no & yes & no & no & yes \\
\hline
\end{tabular}

Notes: Standard errors clustered at country $\times$ sector level in parentheses. + significant at $10 \%$; $*$ significant at $5 \%$; ** significant at $1 \%$. The sample period is 1970-99. The dependent variable is the correlation of the growth rate of output per worker with the rest of the manufacturing sector over ten-year periods: 1970-79, 1980-89, 1990-99. All regressors are in natural logs, trade/output is averaged over the ten-year periods, and output per worker is the ten-year period's initial value. $\mu_{c}$ denotes the country fixed effects. $\mu_{i}$ denotes the sector fixed effects. $\mu_{t}$ denotes the time fixed effects. All specifications are estimated using OLS. 
Table 7. Correlation of Annual Growth of Quantity per Worker and of Prices with Rest of the Manufacturing Sector: Cross-Sectional Results

\begin{tabular}{lcccccc}
\hline \hline \multicolumn{7}{c}{ I. Quantity per Worker } \\
& $(1)$ & $(2)$ & $(3)$ & $(4)$ & $(5)$ & $(6)$ \\
\hline Trade/Output & $-0.037^{* *}$ & $-0.052^{* *}$ & $-0.020^{* *}$ & $-0.021^{*}$ & -0.010 & $-0.129^{* *}$ \\
& $(0.006)$ & $(0.008)$ & $(0.006)$ & $(0.010)$ & $(0.033)$ & $(0.047)$ \\
Output per worker & $-0.022^{*}$ & 0.023 & $-0.053^{* *}$ & -0.025 & -0.022 & $-0.056^{*}$ \\
& $(0.011)$ & $(0.014)$ & $(0.011)$ & $(0.019)$ & $(0.020)$ & $(0.024)$ \\
\hline Observations & 1378 & 1378 & 1378 & 1378 & 1378 & 1378 \\
$R^{2}$ & 0.026 & 0.109 & 0.256 & 0.315 & - & - \\
\hline$\mu_{c}$ & no & no & yes & yes & yes & yes \\
$\mu_{i}$ & no & yes & no & yes & yes & yes \\
Estimation & OLS & OLS & OLS & OLS & IV-log-linear & IV-PMLE \\
\hline \multirow{5}{*}{ Trade/Output } & & & II. Price & & & \\
& $-0.044^{* *}$ & $-0.050^{* *}$ & $-0.042^{* *}$ & $-0.042^{* *}$ & $-0.092^{* *}$ & $-0.099^{*}$ \\
Output per worker & $(0.006)$ & $(0.008)$ & $(0.006)$ & $(0.010)$ & $(0.029)$ & $(0.046)$ \\
& 0.014 & $0.084 * *$ & $-0.041^{* *}$ & -0.015 & -0.030 & -0.032 \\
\hline Observations & $(0.010)$ & $(0.014)$ & $(0.009)$ & $(0.017)$ & $(0.019)$ & $(0.021)$ \\
$R^{2}$ & 1375 & 1375 & 1375 & 1375 & 1375 & 1375 \\
\hline$\mu_{c}$ & 0.050 & 0.148 & 0.376 & 0.439 & - & - \\
$\mu_{i}$ & no & no & yes & yes & yes & yes \\
\hline Estimation & no & yes & no & yes & yes & yes \\
\hline
\end{tabular}

Notes: Robust standard errors in parentheses. + significant at 10\%; significant at 5\%; ** significant at $1 \%$. The sample period is 1970-99. The dependent variable is the correlation of the growth rate of quantity per worker or prices with the rest of the manufacturing sector, 1970-99. All regressors are in natural logs, trade/output is the period average, and output per worker is the period's initial value. $\mu_{c}$ denotes the country fixed effects. $\mu_{i}$ denotes the sector fixed effects. IV-log-linear uses as instrument the predicted trade shares based on the log-linear gravity model. IV-PMLE uses as instrument predicted trade shares based on the gravity model applied to positive and zero trade flows using the Poisson Pseudo-Maximum Likelihood estimator. 
Table 8. Specialization and Trade Openness at the Country Level

\begin{tabular}{lcccccc}
\hline \hline & $(1)$ & $(2)$ & $(3)$ & $(4)$ & $(5)$ & $(6)$ \\
\hline Manuf. Trade/Output & $0.327^{* *}$ & $0.334^{* *}$ & $0.317^{*}$ & $0.377^{* *}$ & $0.181^{* *}$ & $0.280^{* *}$ \\
& $(0.080)$ & $(0.083)$ & $(0.126)$ & $(0.113)$ & $(0.050)$ & $(0.081)$ \\
GDP per capita & & -0.081 & & $-0.099+$ & 0.092 & 0.060 \\
& & $(0.056)$ & & $(0.055)$ & $(0.060)$ & $(0.067)$ \\
Herfindahl of exports & & & & & $0.561 * *$ & $0.491^{* *}$ \\
& & & & & $(0.113)$ & $(0.125)$ \\
Constant & $-2.135^{* *}$ & $-1.412^{* *}$ & $-2.162^{* *}$ & $-1.264^{* *}$ & $-2.081 * *$ & $-1.881^{* *}$ \\
& $(0.071)$ & $(0.460)$ & $(0.087)$ & $(0.460)$ & $(0.355)$ & $(0.400)$ \\
\hline Observations & 60 & 59 & 57 & 57 & 59 & 57 \\
$R^{2}$ & 0.204 & 0.227 & - & - & 0.626 & - \\
\hline Estimation & OLS & OLS & IV & IV & OLS & IV \\
\hline
\end{tabular}

Notes: Robust standard errors in parentheses. + significant at 10\%; * significant at 5\%; ** significant at 1\%. The sample period is 1970-99. The dependent variable is the log Herfindahl index of manufacturing production shares (averaged over the period). All regressors are in natural logs and are period averages. In the instrumental variables regressions, the instrument for trade openness is the natural openness from Frankel and Romer (1999). 
Table 9. Volatility, Correlation and Specialization Coefficients Across Decades

\begin{tabular}{|c|c|c|c|}
\hline \multicolumn{4}{|c|}{ Sector Volatility } \\
\hline \multirow{4}{*}{ Trade/Output } & $(1)$ & (2) & (3) \\
\hline & $1970 \mathrm{~s}$ & $1980 \mathrm{~s}$ & $1990 \mathrm{~s}$ \\
\hline & $0.167 * *$ & $0.168 * *$ & $0.219 * *$ \\
\hline & $(0.031)$ & $(0.033)$ & $(0.045)$ \\
\hline Observations & 1422 & 1475 & 1481 \\
\hline$R^{2}$ & 0.625 & 0.668 & 0.492 \\
\hline \multicolumn{4}{|c|}{ Comovement } \\
\hline \multirow{4}{*}{ Trade/Output } & (1) & (2) & (3) \\
\hline & $1970 \mathrm{~s}$ & $1980 \mathrm{~s}$ & 1990s \\
\hline & $-0.035^{*}$ & $-0.043 * *$ & $-0.051 * *$ \\
\hline & $(0.014)$ & $(0.016)$ & $(0.017)$ \\
\hline Observations & 1396 & 1438 & 1465 \\
\hline$R^{2}$ & 0.259 & 0.281 & 0.286 \\
\hline \multicolumn{4}{|c|}{ Specialization } \\
\hline \multirow{4}{*}{ Trade/Output } & (1) & (2) & (3) \\
\hline & $1970 \mathrm{~s}$ & $1980 \mathrm{~s}$ & $1990 \mathrm{~s}$ \\
\hline & 0.174 & $0.340 * *$ & $0.459 * *$ \\
\hline & $(0.119)$ & $(0.112)$ & $(0.135)$ \\
\hline Observations & 53 & 54 & 54 \\
\hline$R^{2}$ & - & - & - \\
\hline
\end{tabular}

Notes: Robust standard errors in parentheses. + significant at $10 \%$; * significant at 5\%; ** significant at $1 \%$. Sector volatility and comovement decade regressions run with country and sector fixed effects, corresponding to column (4) of Tables 1 and 5. Specialization decade regressions run using IV, corresponding to column (4) of Table 8 . 
Table 10. Cross-Country and Cross-Decade Impacts of Changes in Openness

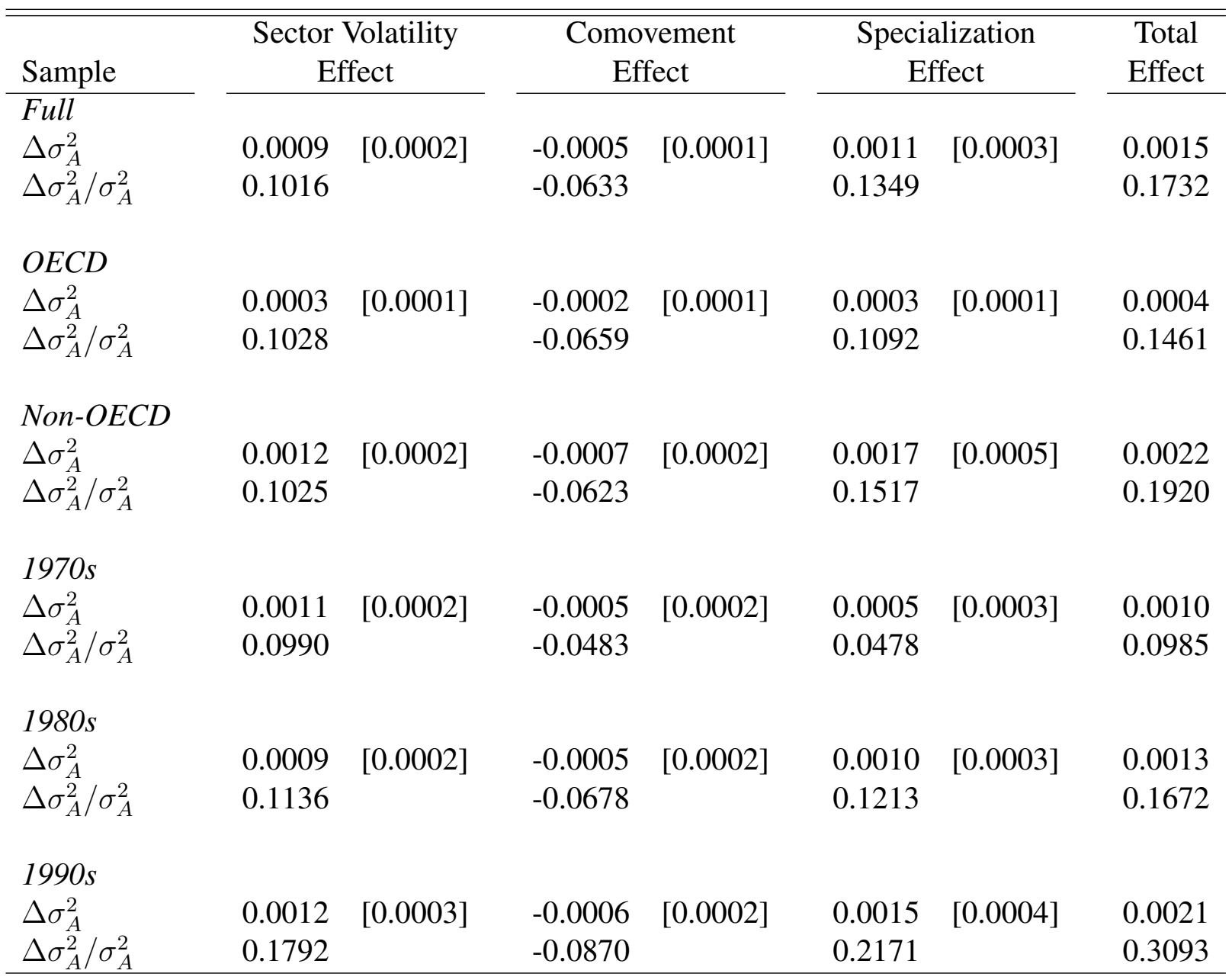

Notes: This table reports the estimated change in aggregate volatility, in absolute terms $\left(\Delta \sigma_{A}^{2}\right)$, and relative to the average aggregate volatility in the sample $\left(\Delta \sigma_{A}^{2} / \sigma_{A}^{2}\right)$. The first six columns report the individual effects. Standard errors for components of $\Delta \sigma_{A}$ are presented in brackets in the column next to point estimates. The last column reports the combined effect. The trade opening used in this table is equivalent to moving from the $25^{\text {th }}$ to $75^{\text {th }}$ percentile of trade openness in the sample. 
Table 11. The Impact of Changes in Openness Evaluated at Different Percentiles of the Data

\begin{tabular}{|c|c|c|c|c|c|c|c|}
\hline \multirow[b]{2}{*}{ Baseline } & \multicolumn{2}{|c|}{$\begin{array}{c}\text { Sector Volatility } \\
\text { Effect }\end{array}$} & \multicolumn{2}{|c|}{$\begin{array}{c}\text { Comovement } \\
\text { Effect }\end{array}$} & \multicolumn{2}{|c|}{$\begin{array}{c}\text { Specialization } \\
\text { Effect }\end{array}$} & \multirow{2}{*}{$\begin{array}{c}\begin{array}{c}\text { Total } \\
\text { Effect }\end{array} \\
0.0015\end{array}$} \\
\hline & 0.0009 & [0.0002] & -0.0005 & {$[0.0001]$} & 0.0011 & {$[0.0003]$} & \\
\hline \multicolumn{8}{|l|}{$\sigma_{i}^{2}$} \\
\hline 25th pctile & 0.0004 & {$[0.0001]$} & -0.0003 & {$[0.0001]$} & 0.0004 & {$[0.0001]$} & 0.0005 \\
\hline 75th pctile & 0.0012 & [0.0002] & -0.0006 & [0.0002] & 0.0017 & {$[0.0005]$} & 0.0023 \\
\hline Ratio 75th/25th & 2.89 & & 1.95 & & 4.44 & & 4.87 \\
\hline \multicolumn{8}{|l|}{$\rho_{i, A-i}$} \\
\hline 25th pctile & 0.0008 & {$[0.0001]$} & -0.0005 & {$[0.0001]$} & 0.0012 & {$[0.0004]$} & 0.0014 \\
\hline 75th pctile & 0.0010 & [0.0002] & -0.0005 & {$[0.0001]$} & 0.0011 & {$[0.0003]$} & 0.0015 \\
\hline Ratio 75th/25th & 1.26 & & 1.00 & & 0.89 & & 1.05 \\
\hline \multicolumn{8}{|c|}{$h$} \\
\hline 25th pctile & 0.0007 & {$[0.0001]$} & -0.0006 & {$[0.0001]$} & 0.0007 & {$[0.0002]$} & 0.0009 \\
\hline 75th pctile & 0.0009 & [0.0002] & -0.0005 & {$[0.0001]$} & 0.0012 & [0.0004] & 0.0016 \\
\hline Ratio 75th/25th & 1.30 & & 0.95 & & 1.64 & & 1.82 \\
\hline
\end{tabular}

Notes: This table reports the estimated change in aggregate volatility in absolute terms $\left(\Delta \sigma_{A}^{2}\right)$, while evaluating $\sigma^{2}, \rho$, and $h$ at the $25^{\text {th }}$ and $75^{\text {th }}$ percentiles of their respective distributions. It also reports the ratio of the two. The first six columns report the individual effects. Standard errors for components of $\Delta \sigma_{A}$ are presented in brackets in the column next to point estimates. The last column reports the combined effect. The trade opening used in this table is equivalent to moving from the $25^{\text {th }}$ to $75^{\text {th }}$ percentile of trade openness in the sample. 
Figure 1. Volatility and Openness in the 1990s

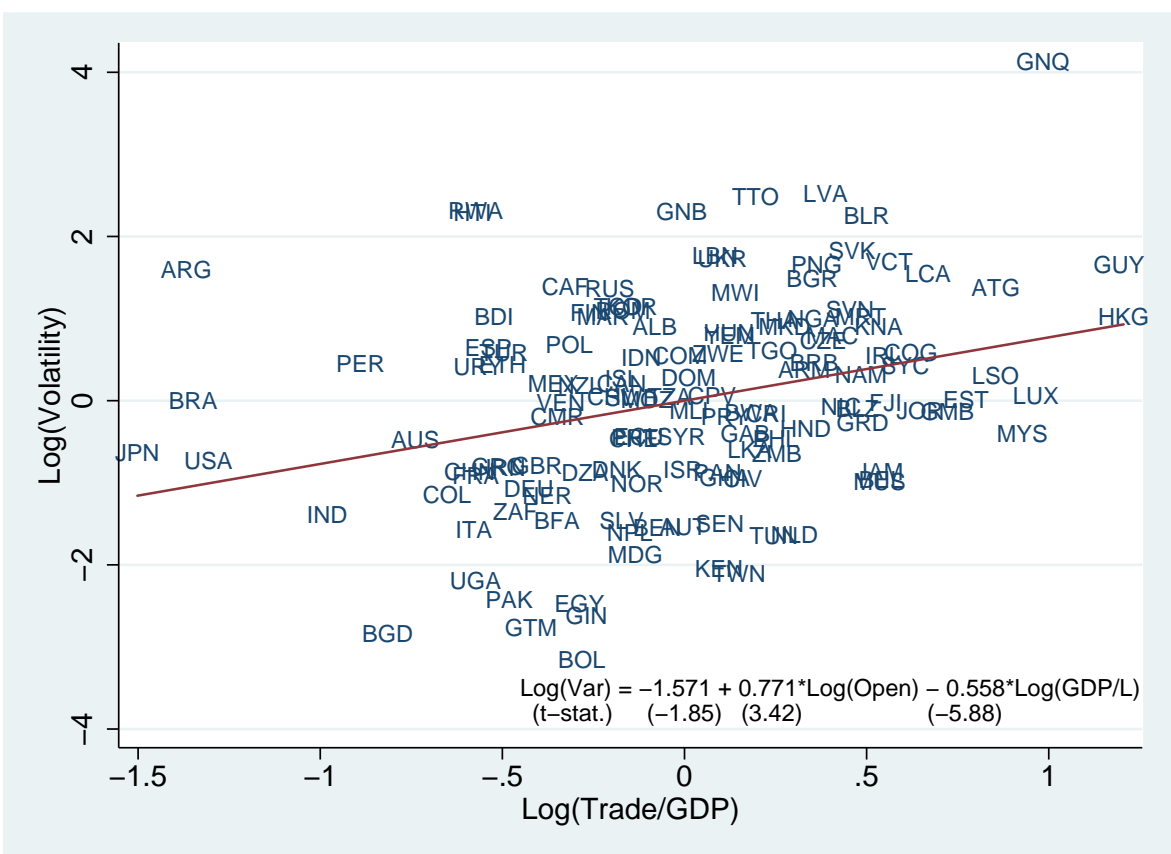

Notes: This figure reports the partial correlation between trade openness and macroeconomic volatility, after controlling for average per capita income. The estimated equation is reported at the bottom of the plot. Volatility is calculated using annual growth rates over 1990-99 for per-capita GDP, and trade openness is the average of imports plus exports divided by GDP over the same period. Source: Penn World Tables.

Figure 2. Comparison of Manufacturing and Aggregate Volatility

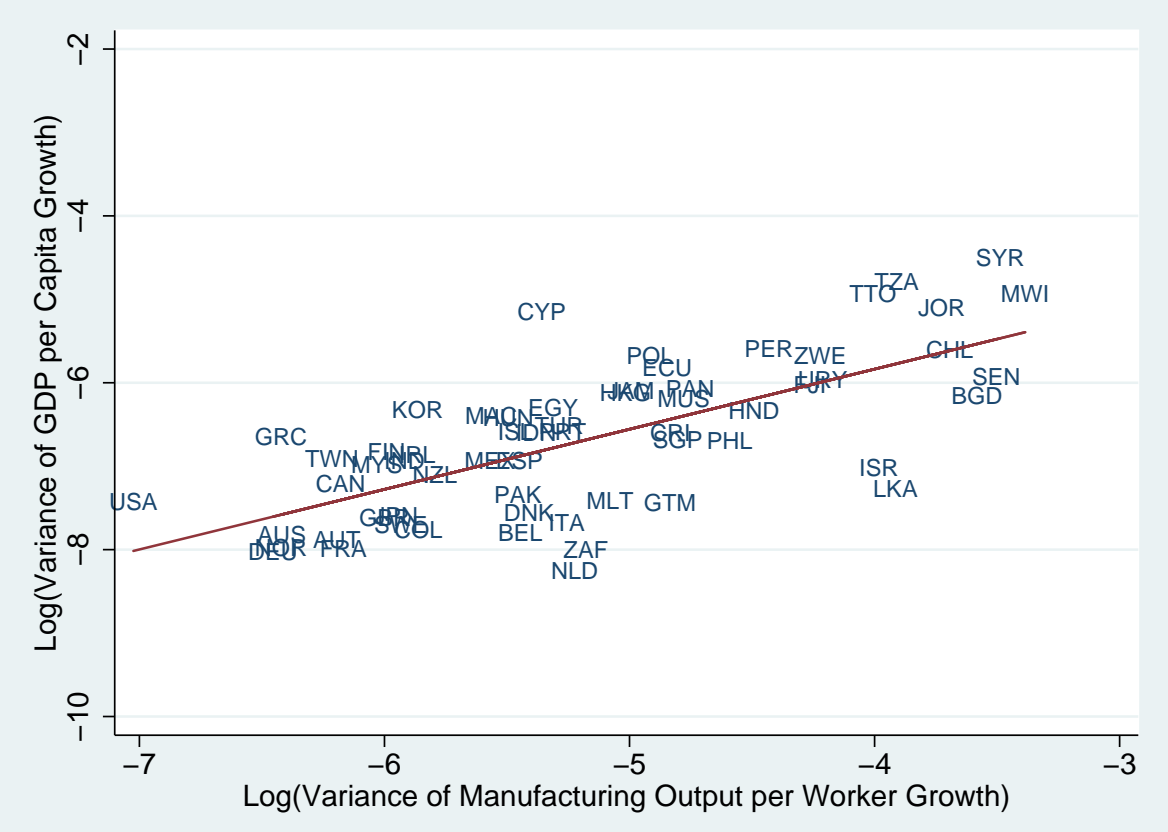

Notes: This figure reports the scatterplot of the volatility of per capita GDP from the Penn World Tables against the volatility of total manufacturing output per worker from UNIDO. Volatility is calculated using annual growth rates over 1970-99. 
Figure 3. Manufacturing Output Volatility and Openness

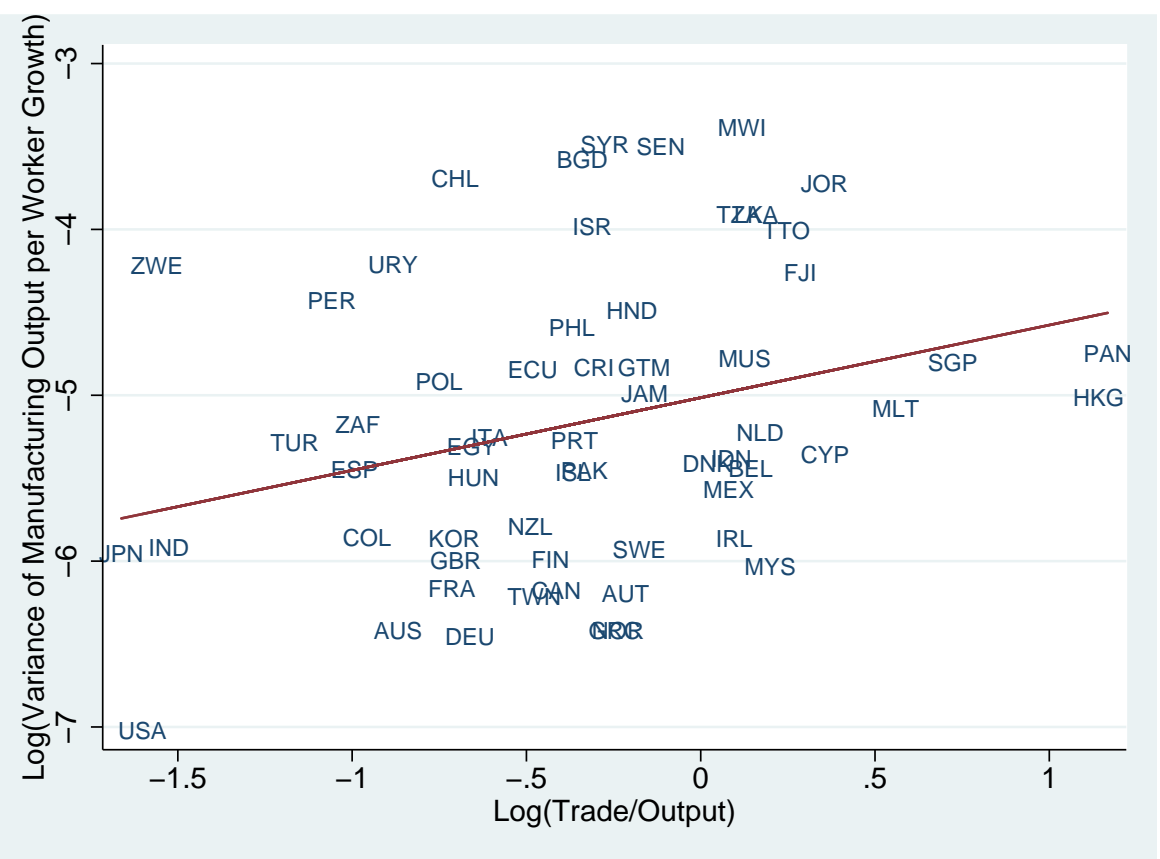

Notes: This figure reports the scatterplot of the volatility of total manufacturing output per worker against manufacturing trade as a share of output. Manufacturing output volatility is calculated using annual growth rates over 1970-99, and the manufacturing trade-to-output ratio is an average over 1970-99.

Figure 4. Trade and Specialization

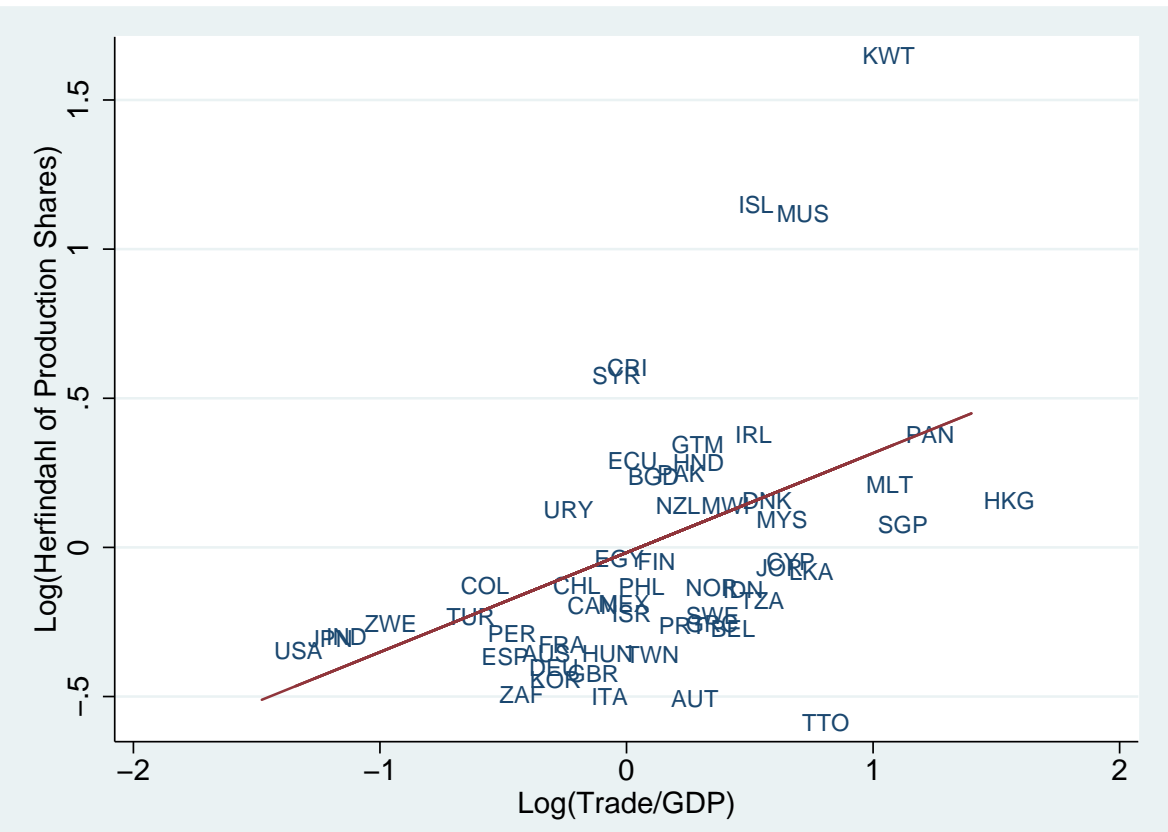

Notes: This figure reports the partial correlations between the Herfindahl of production shares and manufacturing trade as a share of output, after controlling for per capita GDP. The Herfindahl of production shares and the manufacturing trade-to-output measures ratio are averages for 1970-99. 


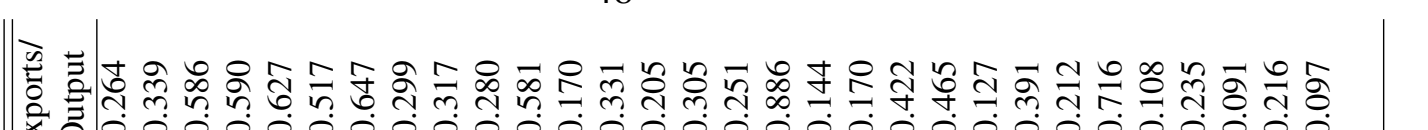

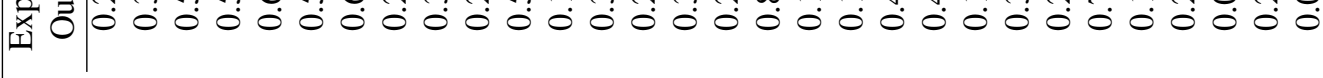

के

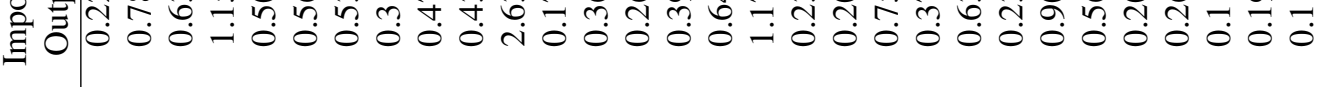

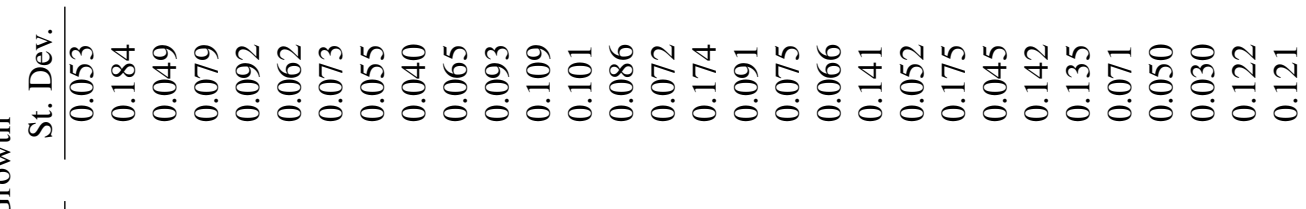

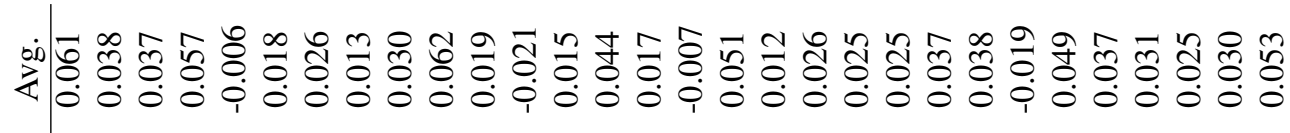

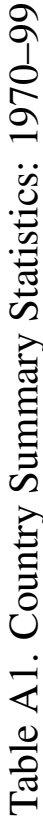

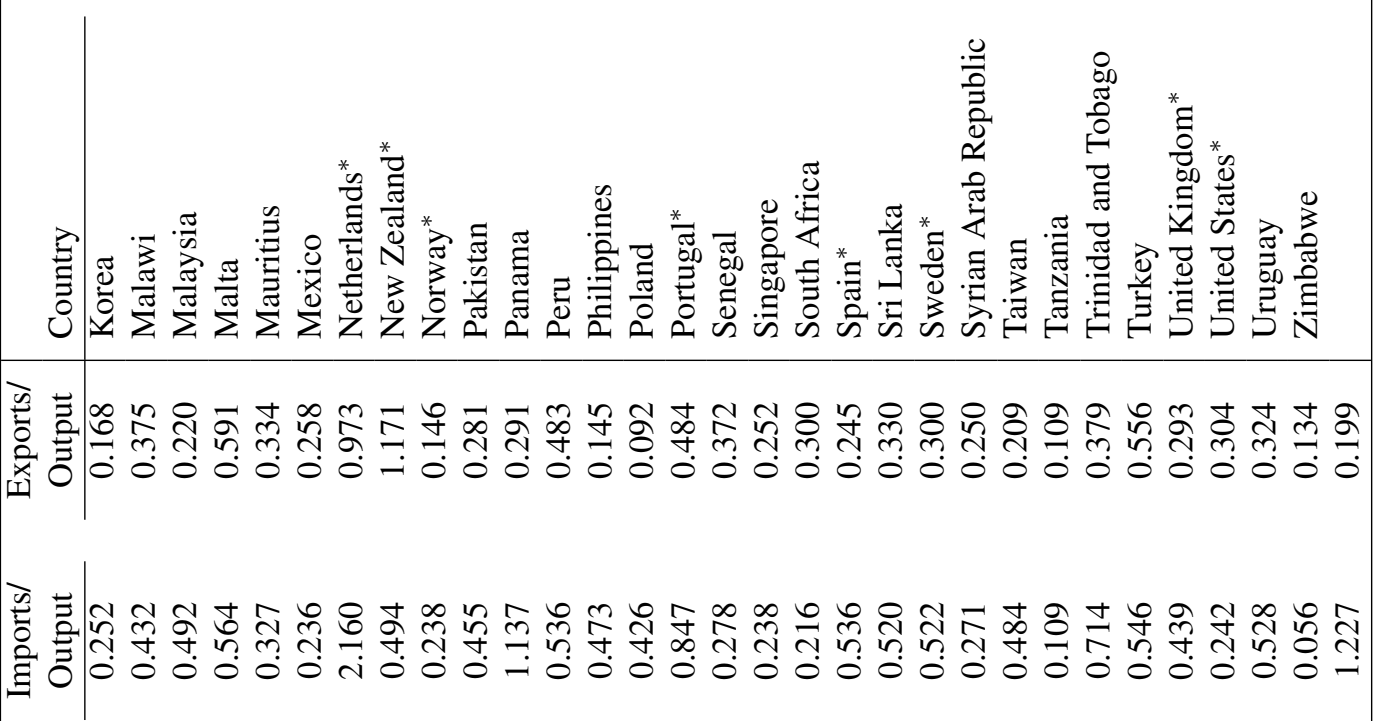

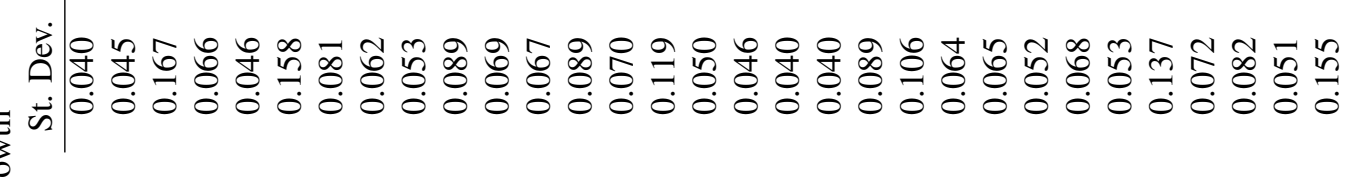
党

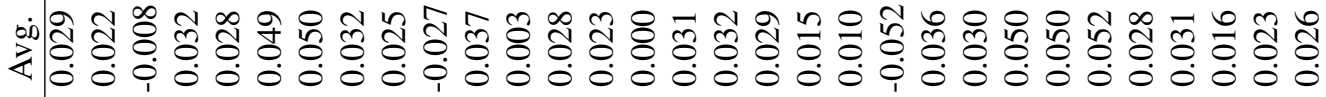

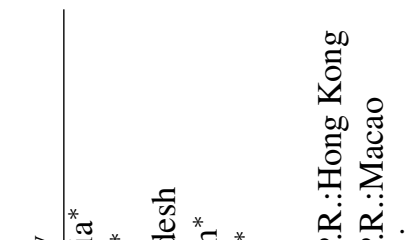

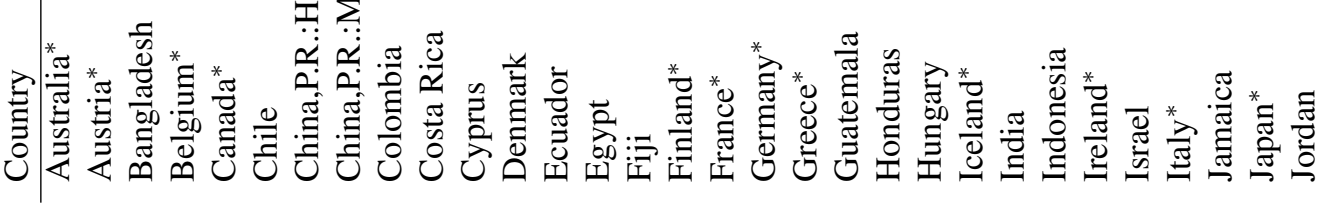


Table A2. Sector Summary Statistics: 1970-99

\begin{tabular}{|c|c|c|c|c|c|}
\hline \multirow[b]{2}{*}{ ISIC } & \multirow[b]{2}{*}{ Sector Name } & \multicolumn{2}{|c|}{ Growth } & \multirow{2}{*}{$\begin{array}{c}\text { Imports/ } \\
\text { Output }\end{array}$} & \multirow{2}{*}{$\begin{array}{c}\text { Exports/ } \\
\text { Output }\end{array}$} \\
\hline & & Avg. & St. Dev. & & \\
\hline 311 & Food products & 0.018 & 0.115 & 0.298 & 0.228 \\
\hline 313 & Beverages & 0.035 & 0.134 & 0.180 & 0.107 \\
\hline 314 & Tobacco & 0.051 & 0.181 & 0.591 & 0.158 \\
\hline 321 & Textiles & 0.025 & 0.123 & 1.127 & 0.349 \\
\hline 322 & Wearing apparel, except footwear & 0.025 & 0.114 & 0.797 & 1.047 \\
\hline 323 & Leather products & 0.028 & 0.174 & 2.116 & 0.933 \\
\hline 324 & Footwear, except rubber or plastic & 0.030 & 0.156 & 1.997 & 0.374 \\
\hline 331 & Wood products, except furniture & 0.031 & 0.166 & 1.013 & 0.302 \\
\hline 332 & Furniture, except metal & 0.034 & 0.155 & 0.315 & 0.249 \\
\hline 341 & Paper and products & 0.034 & 0.149 & 0.729 & 0.184 \\
\hline 342 & Printing and publishing & 0.039 & 0.131 & 0.173 & 0.065 \\
\hline 351 & Industrial chemicals & 0.057 & 0.206 & 2.226 & 0.565 \\
\hline 352 & Other chemicals & 0.041 & 0.132 & 0.607 & 0.261 \\
\hline 353 & Petroleum refineries & 0.061 & 0.255 & 0.643 & 0.193 \\
\hline 354 & Misc. petroleum and coal products & 0.049 & 0.251 & 1.433 & 0.489 \\
\hline 355 & Rubber products & 0.030 & 0.157 & 1.822 & 0.332 \\
\hline 356 & Plastic products & 0.031 & 0.136 & 0.324 & 0.220 \\
\hline 361 & Pottery, china, earthenware & 0.038 & 0.168 & 1.740 & 0.435 \\
\hline 362 & Glass and products & 0.047 & 0.150 & 2.273 & 0.562 \\
\hline 369 & Other non-metallic mineral products & 0.044 & 0.141 & 0.446 & 0.304 \\
\hline 371 & Iron and steel & 0.034 & 0.182 & 1.258 & 0.282 \\
\hline 372 & Non-ferrous metals & 0.036 & 0.212 & 1.989 & 1.440 \\
\hline 381 & Fabricated metal products & 0.028 & 0.142 & 0.577 & 0.183 \\
\hline 382 & Machinery, except electrical & 0.037 & 0.154 & 12.188 & 3.878 \\
\hline 383 & Machinery, electric & 0.043 & 0.151 & 2.205 & 0.484 \\
\hline 384 & Transport equipment & 0.051 & 0.181 & 8.130 & 1.499 \\
\hline 385 & Professional \& scientific equipment & 0.034 & 0.179 & 13.210 & 1.642 \\
\hline 390 & Other manufactured products & 0.030 & 0.174 & 1.299 & 1.251 \\
\hline
\end{tabular}

Notes: 'Growth' is the real manufacturing output per worker growth rate computed annually over 197099. Imports and exports to output are averages of total manufacturing imports and exports divided by total manufacturing output. These summary statistics are calculated based on the sample used in the crosssectional regressions of Table 1. 


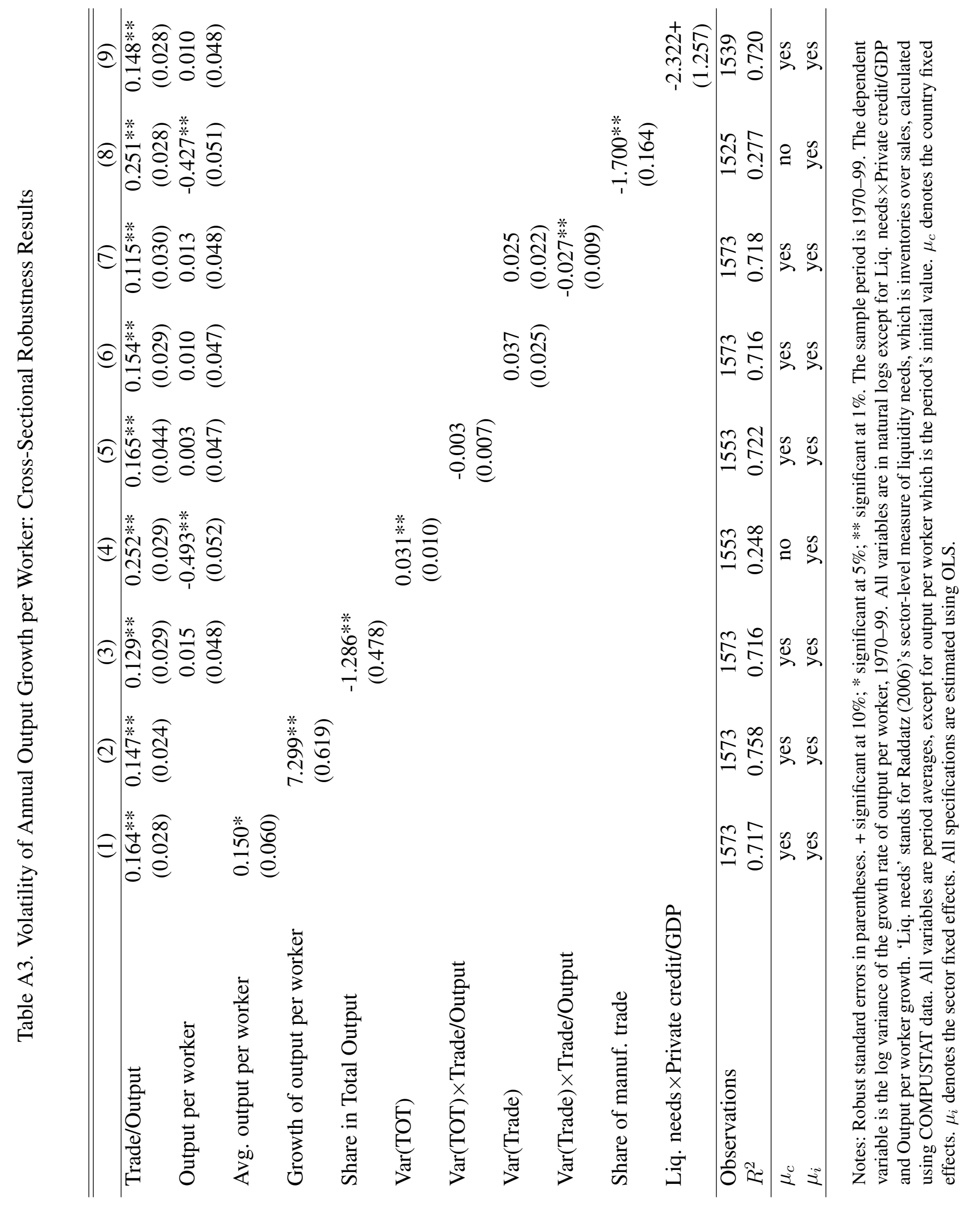




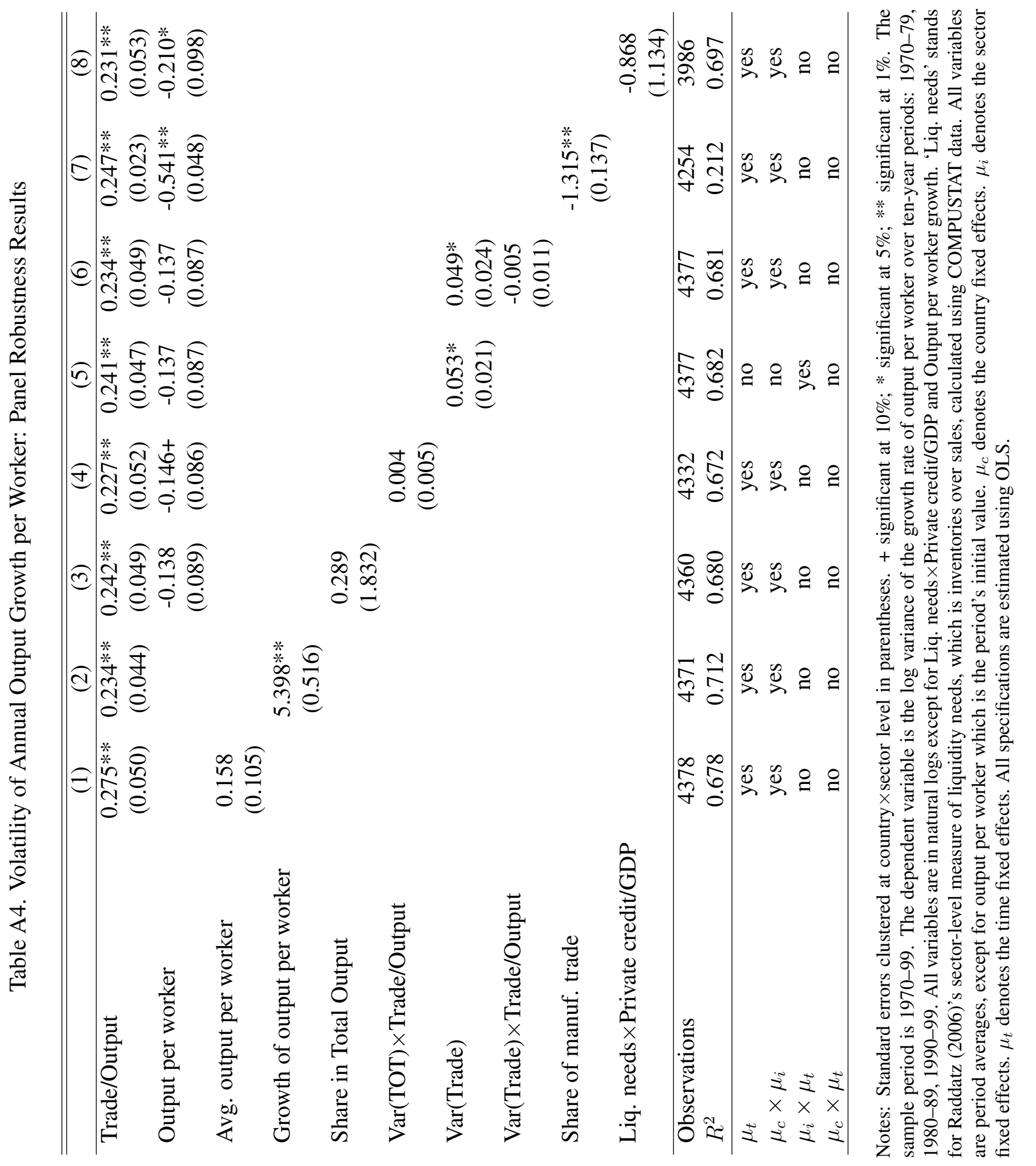




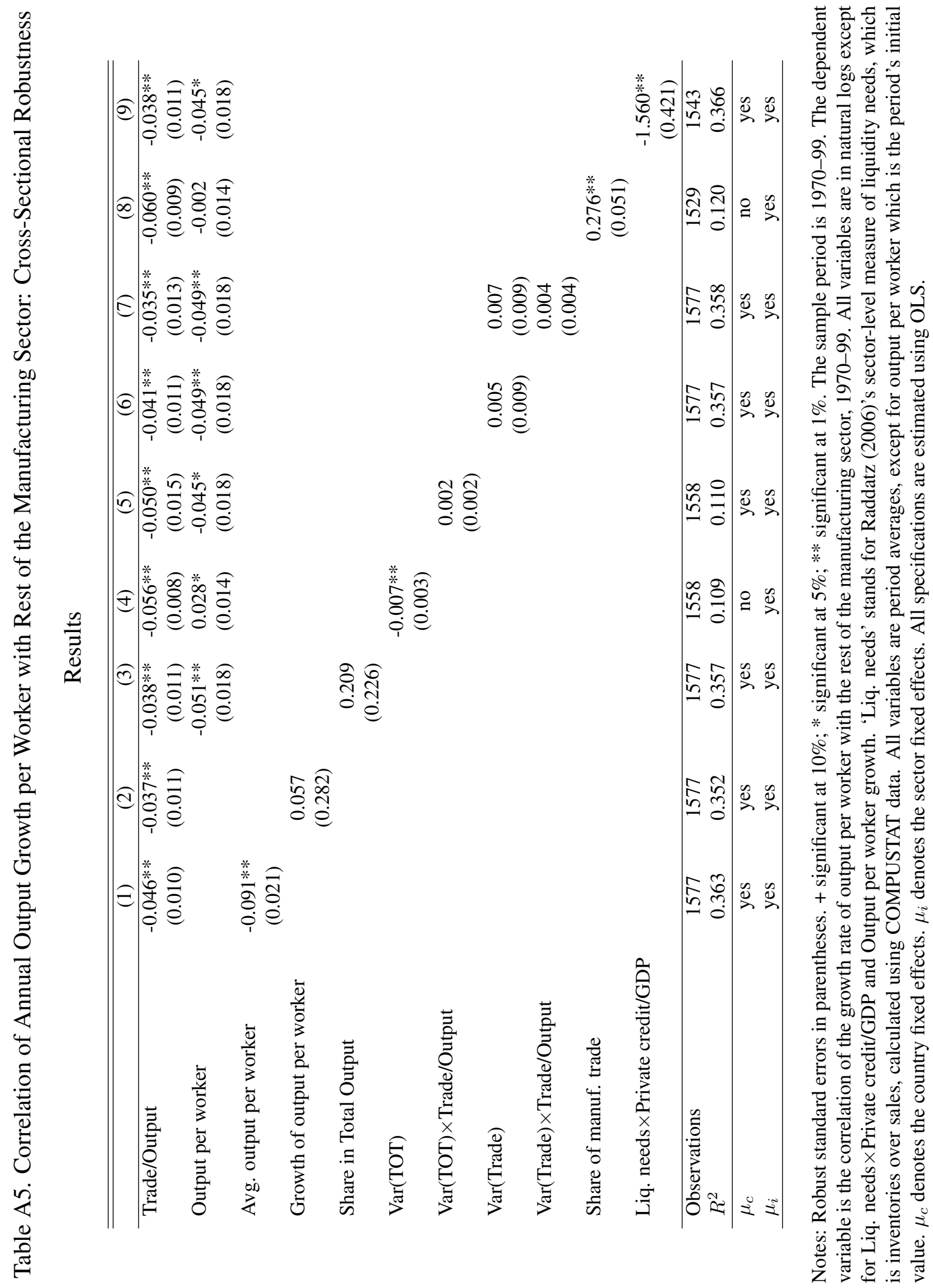




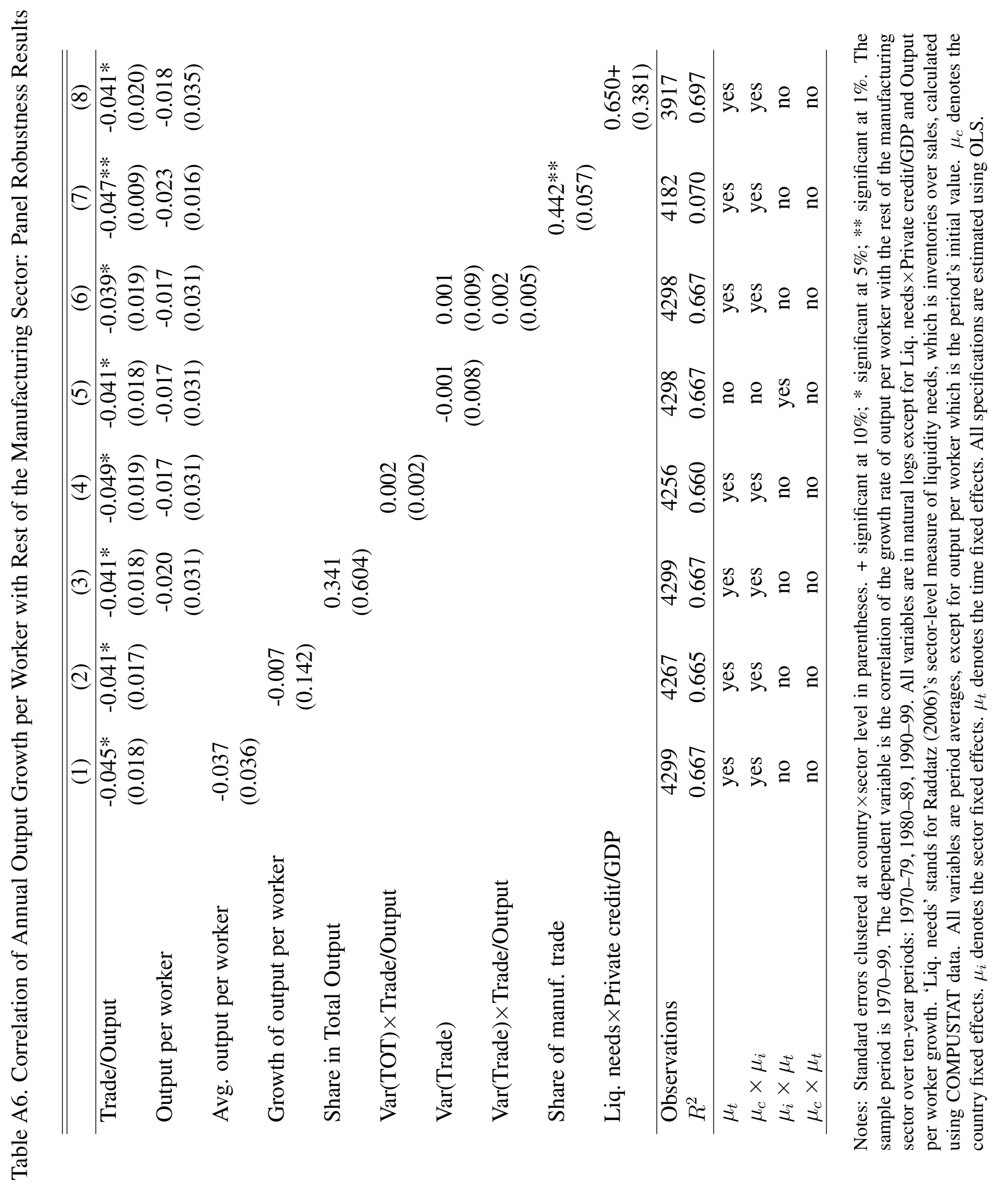




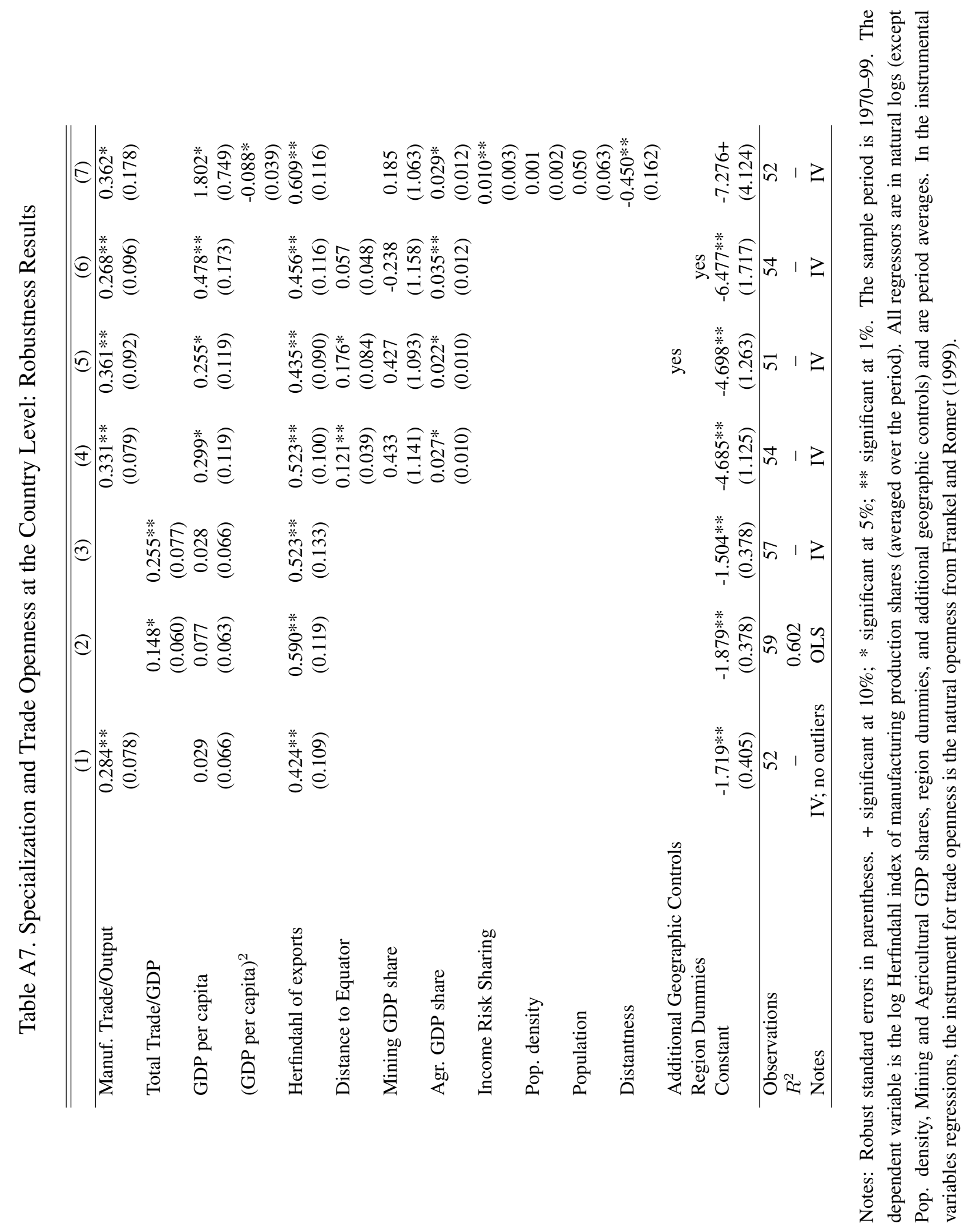


Figure A1. Sector-Level Gravity Coefficients
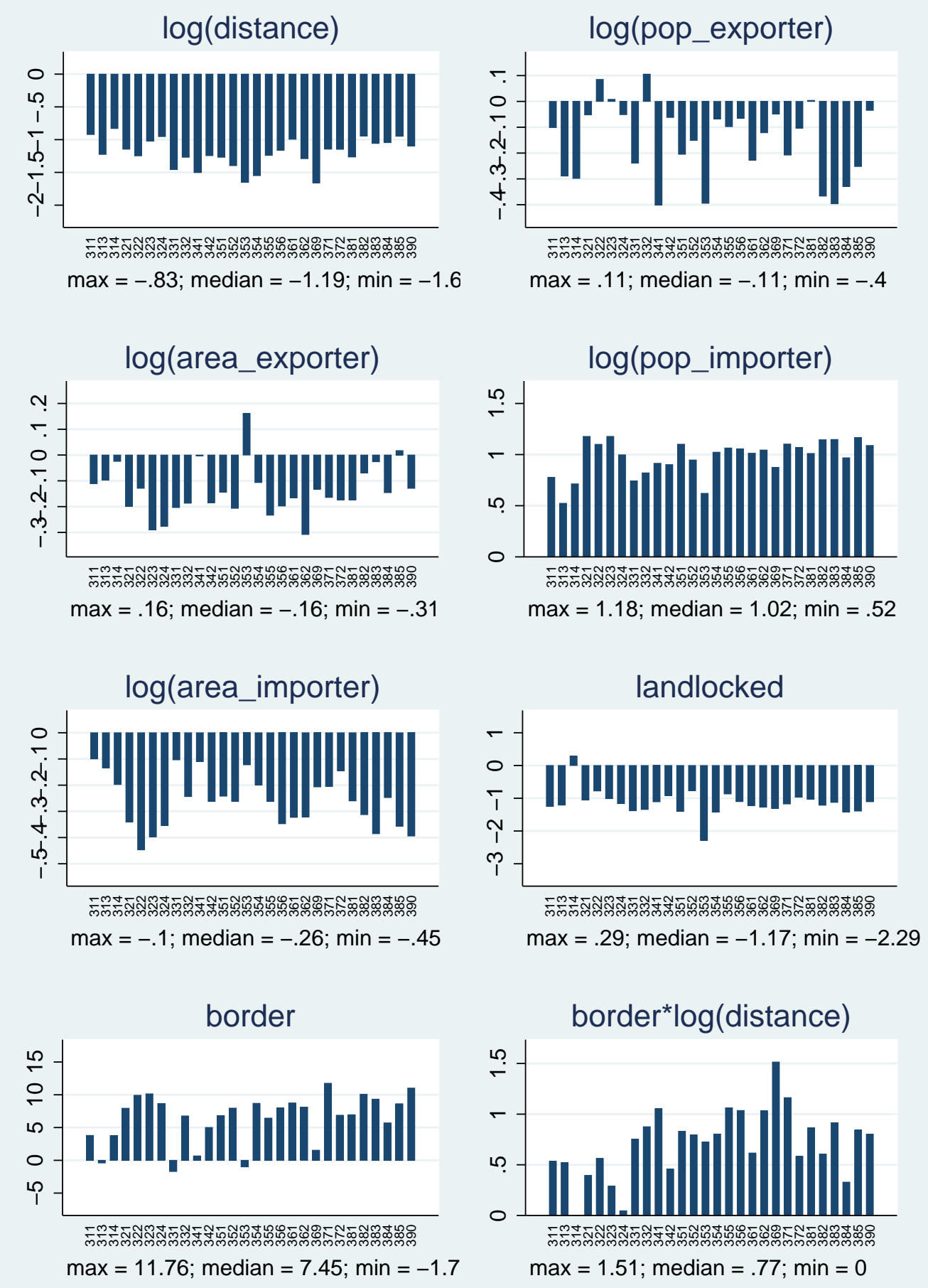

Notes: This figure reports the sector-level gravity coefficients from estimating equation (A.1). Each subplot is a coefficient, while each bar within the subplot represents a sector. 
Figure A1. Sector-Level Gravity Coefficients (concluded)
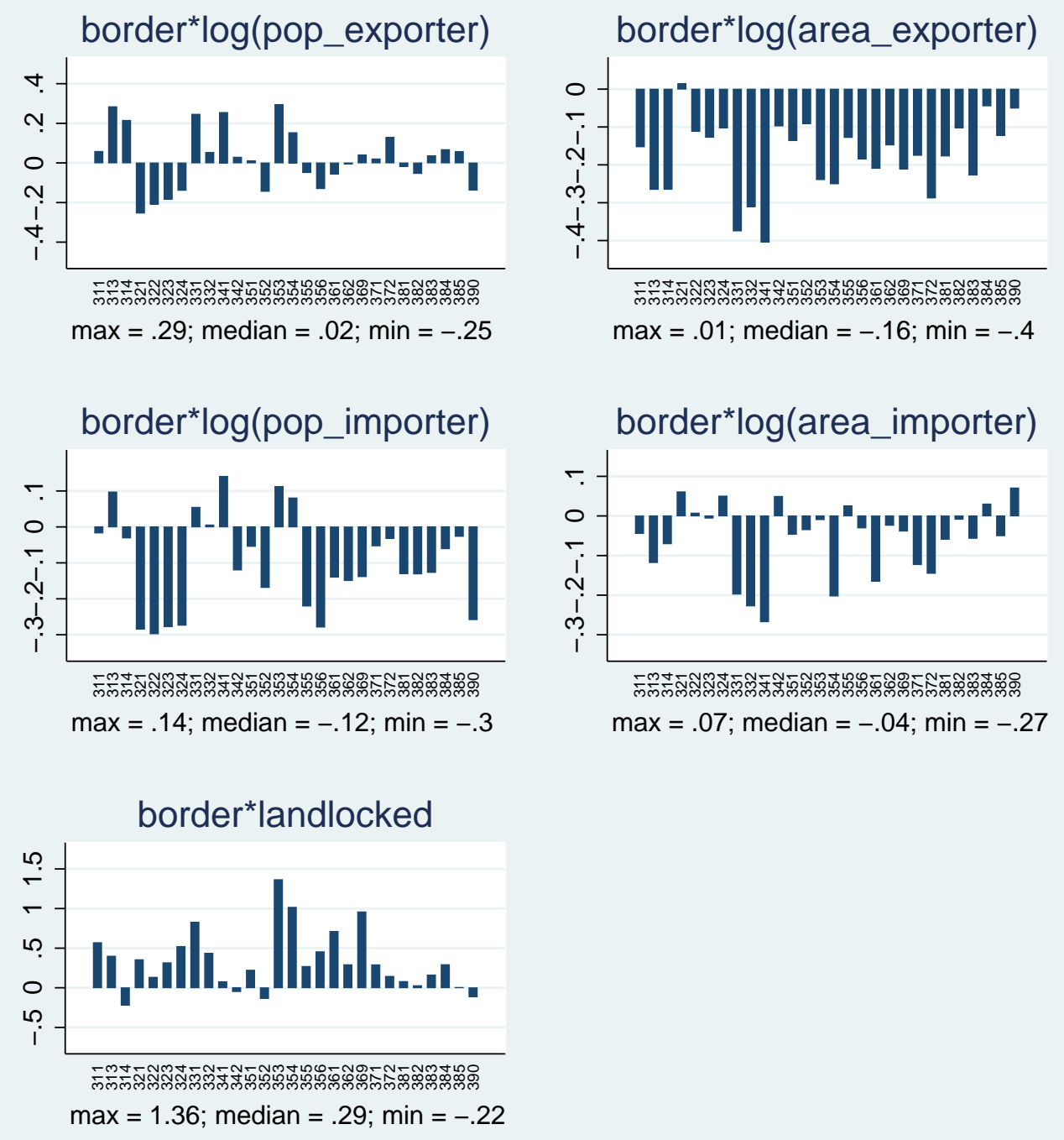

Notes: This figure reports the sector-level gravity coefficients from estimating equation (A.1). Each subplot is a coefficient, while each bar within the subplot represents a sector. 


\section{REFERENCES}

Anderson, James and Eric van Wincoop, 2003, "Gravity with Gravitas: a Solution to the Border Puzzle,” American Economic Review, Vol. 93, No. 1, pp. 170-92. and __ , 2004, “Trade Costs," Journal of Economic Literature, Vol. 42, No. 3, pp. $691-751$.

Backus, David K., Patrick J. Kehoe, and Finn E. Kydland, 1992, "International Real Business Cycles,” Journal of Political Economy, Vol. 100, No. 4 (August), pp. 745-75.

Barlevy, Gadi, 2004, "The Costs of Business Cycles Under Endogenous Growth," American Economic Review, Vol. 94, No. 4 (September), pp. 964-90.

Baxter, Marianne and Michael Kouparitsas, 2005, "Determinants of Business Cycle Comovement: A Robust Analysis," Journal of Monetary Economics, Vol. 52, No. 1 (January), pp. 113-157.

Beck, Thorsten, Aslı Demirgüç-Kunt, and Ross Levine, 2000, “A New Database on Financial Development and Structure," World Bank Economic Review, Vol. 14, No. 3, pp. 597-605.

Bejan, Maria, 2004, “Trade Openness and Output Volatility,” (October). Mimeo, ITAM.

Bekaert, Geert, Campbell R. Harvey, and Christian Lundblad, 2006, "Growth volatility and financial liberalization," Journal of International Money and Finance, Vol. 25, No. 3 (April), pp. 370-403.

Buch, Claudia M., Jörg Döpke, and Harald Strotmann, 2006, “Does Export Openness Increase Firm-Level Volatility?" Mimeo, University of Tübingen and Deutsche Bundesbank.

Burstein, Ariel, Christopher Kurz, and Linda L. Tesar, 2004, "International Trade, Production Sharing and the Transmission of Business Cycles?," (November). Mimeo, UCLA and the University of Michigan.

Cavallo, Eduardo A., 2005, "Openness to Trade and Output Volatility: A Reassessment." Mimeo, Harvard University.

Cecchetti, Stephen G., Alfonso Flores-Lagunes, and Stefan Krause, 2006, "Assessing the Sources of Changes in the Volatility of Real Growth," (January). NBER Working Paper No. 11946.

Chaney, Thomas, 2006, “Distorted Gravity: Heterogeneous Firms, Market Structure, and the Geography of International Trade.” Mimeo, University of Chicago.

Comín, Diego and Thomas Philippon, “The Rise in Firm-Level Volatility: Causes and Consequences," 2006, in Mark Gertler and Kenneth S. Rogoff, eds., NBER Macroeconomics Annual 2005, Vol. 20 (Cambridge, Mass.: The MIT Press), chapter 1, pp. 167-201. 
di Giovanni, Julian and Andrei A. Levchenko, 2007, "The Risk Content of Exports: a Portfolio View of International Trade." Mimeo, IMF.

Do, Quy-Toan and Andrei A. Levchenko, 2007, "Comparative Advantage, Demand for External Finance, and Financial Development," Journal of Financial Economics, Vol. 86, No. 3 (December), pp. 796834.

Easterly, William, Roumeen Islam, and Joseph E. Stiglitz, "Shaken and Stirred: Explaining Growth Volatility," 2001, in B. Pleskovic and N. Stern, eds., Annual World Bank Conference on Development Economics.

Evans, Carolyn, 2003, "The Economic Significance of National Border Effects," American Economic Review, Vol. 93, No. 4, pp. 1291-1312.

Feenstra, Robert C., Robert E. Lipsey, Haiyan Deng, Alyson C. Ma, and Hengyong Mo, 2005, "World Trade Flows: 1962-2000," (January). NBER Working Paper No. 11040.

Feenstra, Robert, James Markusen, and Andrew Rose, 2001, "Using the Gravity Equation to Differentiate Among Alternative Theories of Trade," Canadian Journal of Economics, Vol. 34, No. 2, pp. 430-47.

Frankel, Jeffrey A. and Andrew K. Rose, 1998, “The Endogeneity of the Optimum Currency Area Criteria,” Economic Journal, Vol. 108, No. 449 (July), pp. 1009-25. and David Romer, 1999, "Does Trade Cause Growth?," American Economic Review, Vol. 89, No. 3 (June), pp. 379-99.

Gabaix, Xavier, 2005, “The Granular Origins of Aggregate Fluctuations,” (January). Mimeo, MIT.

Gavin, Michael and Ricardo Hausmann, "Growth with Equity: The Volatility Connection," 1998, in Nancy Birdsall, Carol Graham, and Richard H. Sabot, eds., Beyond tradeoffs: Market Reforms and Equitable Growth in Latin America, (Washington, DC: Inter-American Development Bank and the Brookings Institution), pp. 91-109.

Helpman, Elhanan, Marc Melitz, and Yona Rubinstein, 2006, “Trading Partners and Trading Volumes.” Mimeo, Harvard University.

Heston, Alan, Robert Summers, and Bettina Aten, 2002, "Penn World Table Version 6.1," (October). Center for International Comparisons at the University of Pennsylvania (CICUP).

Hummels, David, 2001, “Towards a Geography of Trade Costs.” Mimeo, Purdue University.

ILO, 2004, “A Fair Globalization: Creating Opportunities for All.” World Commission on the Social Dimension of Globalization Report, Geneva, Switzerland. 
Imbs, Jean, 2006, "Growth and Volatility," (January). Forthcoming, Journal of Monetary Economics.

and Romain Wacziarg, 2003, "Stages of Diversification," American Economic Review, Vol. 93, No. 1 (March), pp. 63-86.

Kalemli-Ozcan, Sebnem, Bent E. Sørensen, and Oved Yosha, 2003, "Risk Sharing and Industrial Specialization: Regional and International Evidence," American Economic Review, Vol. 93, No. 3 (June), pp. 903-18.

Koren, Miklós and Silvana Tenreyro, 2007, "Volatility and Development," Quarterly Journal of Economics, Vol. 122, No. 1 (February), pp. 243-87.

Kose, M. Ayhan, 2001, "Explaining Business Cycles in Small Open Economies: How Much do World Prices Matter?,' Journal of International Economics, Vol. 56, No. 2 (March), pp. 299-327.

and Kei-Mu Yi, 2006, "Can the Standard International Business Cycle Model Explain the Relation Between Trade and Comovement," Journal of International Economics, Vol. 68, No. 2 (March), pp. 267-95.

_ _ Eswar S. Prasad, and Marco E. Terrones, 2003, "Financial Integration and Macroeconomic Volatility," IMF Staff Papers, Vol. 50, No. Special Issue, pp. 119-41.

Kraay, Aart and Jaume Ventura, 2006, "Comparative Advantage and the Cross-Section of Business Cycles." Forthcoming, Journal of European Economic Association.

Krebs, Tom, Pravin Krishna, and William Mahoney, 2005, “Trade Policy, Income Risk, and Welfare," (November). Mimeo, Syracuse University, John Hopkins University, and the World Bank.

Lai, Huiwen and Daniel Trefler, 2001, “The Gains from Trade with Monopolistic Competition: Specification, Estimation, and Mis-Specification." NBER Working Paper No. 9169.

Laursen, Thomas and Sandeep Mahajan, "Volatility, Income Distribution, and Poverty," 2005, in Joshua Aizenman and Brian Pinto, eds., Managing Economic Volatility and Crises: A Practitioner's Guide, Cambridge University Press New York pp. 101-36.

Long, John and Charles Plosser, 1983, "Real Business Cycles," Journal of Political Economy, Vol. 91, No. 1 (February), pp. 39-69.

Newbery, David M. G. and Joseph E. Stiglitz, 1984, "Pareto Inferior Trade," Review of Economic Studies, Vol. 51, No. 1 (January), pp. 1-12.

Pallage, Stéphane and Michel A. Robe, 2003, "On The Welfare Cost of Economic Fluctuations in Developing Countries," International Economic Review, Vol. 44, No. 2 (May), pp. 677-98. 
Raddatz, Claudio, 2006, "Liquidity Needs and Vulnerability to Financial Underdevelopment," Journal of Financial Economics, Vol. 80, No. 3 (June), pp. 677-722.

Ramey, Garey and Valerie A. Ramey, 1995, "Cross-Country Evidence on the Link Between Volatility and Growth," American Economic Review, Vol. 85, No. 5 (December), pp. 1138-51.

Rauch, James E., 1999, "Networks Versus Markets in International Trade," Journal of International Economics, Vol. 48, No. 1 (June), pp. 7-35. and Vitor Trindade, 2002, "Ethnic Chinese Networks in International Trade," Review of Economics and Statistics, Vol. 84, No. 1, pp. 116-30.

Rodrik, Dani, 1997, Has Globalization Gone Too Far? (Washington, D.C.: Institute for International Economics). , 1998, "Why Do More Open Economies Have Bigger Governments?, Journal of Political Economy, Vol. 106, No. 5 (October), pp. 997-1032.

Santos Silva, J.M.C and Silvana Tenreyro, 2006, "The Log of Gravity," Review of Economics and Statistics, Vol. 88, No. 4, pp. 641-58.

Stock, James H. and Mark W. Watson, "Has the Business Cycle Changed and Why?," 2003, in Mark Gertler and Kenneth S. Rogoff, eds., NBER Macroeconomics Annual 2002, (Cambridge, Mass.: The MIT Press), chapter 4, pp. 159-218.

and Motohiro Yogo, “Testing for Weak Instruments in Linear IV Regression,” 2005, in Donald W.K. Andrews and James H. Stock, eds., Identification and Inference for Econometric Models: Essays in Honor of Thomas Rothenberg, Cambridge University Press Cambridge, UK pp. 80-108.

United Nations Industrial Development Organization, 2006, "Industrial Statistics Database." CD-ROM.

Volosovych, Vadym, 2006, "Financial Market Integration, Risk Sharing, and Institutions: Theory and Evidence," (December). Working Paper 06008, Department of Economics Working Papers, Florida Atlantic University. 